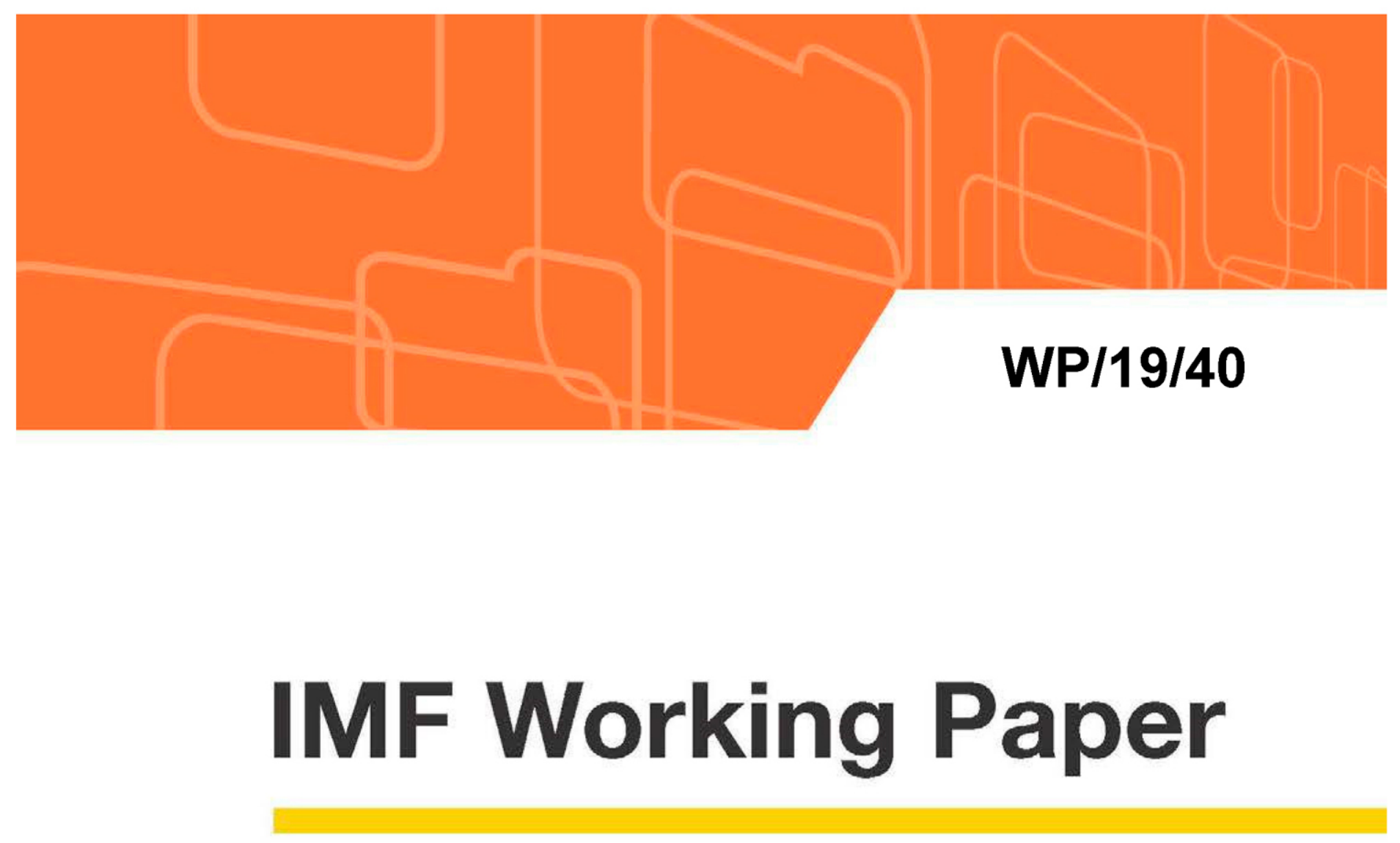

\title{
Are Labor Market Indicators Telling the Truth? Role of Measurement Error in the U.S. Current Population Survey
}

IMF Working Papers describe research in progress by the author(s) and are published to elicit comments and to encourage debate. The views expressed in IMF Working Papers are those of the author(s) and do not necessarily represent the views of the IMF, its Executive Board, or IMF management. 


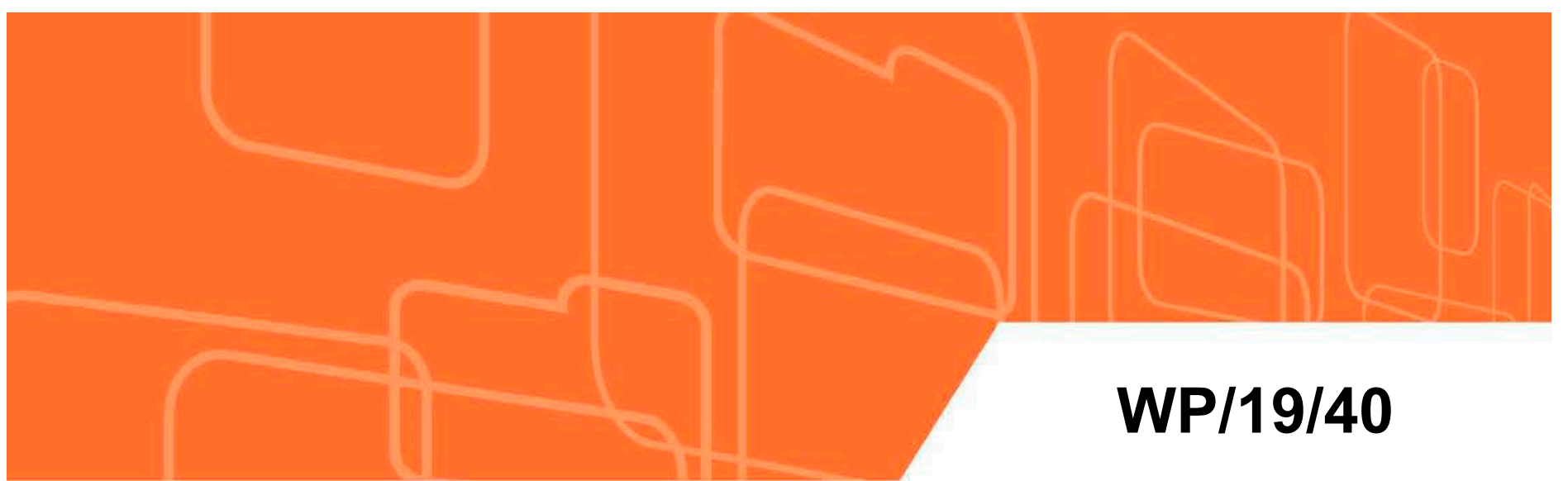

\section{IMF Working Paper}

\section{Are Labor Market Indicators Telling the Truth? Role of Measurement Error in the U.S. Current Population Survey}

by Ippei Shibata

IMF Working Papers describe research in progress by the author(s) and are published to elicit comments and to encourage debate. The views expressed in IMF Working Papers are those of the author(s) and do not necessarily represent the views of the IMF, its Executive Board, or IMF management. 


\title{
IMF Working Paper
}

Western Hemisphere Department

\section{Are Labor Market Indicators Telling the Truth? Role of Measurement Error in the U.S. Current Population Survey Prepared by Ippei Shibata ${ }^{1}$}

Authorized for distribution by Inci Otker

February 2019

IMF Working Papers describe research in progress by the author(s) and are published to elicit comments and to encourage debate. The views expressed in the IMF Working Papers are those of the author(s) and do not necessarily represent the views of the IMF, its Executive Board, or IMF management.

\begin{abstract}
Labor market indicators are critical for policymakers, but measurement error in labor force survey data is known to be substantial. In this paper, I quantify the implications of classification errors in the U.S. Current Population Survey (CPS), in which respondents misreport their true labor force status. Once I correct for measurement error using a latent variable approach, the unemployment rate is on average 0.8 percentage points (ppts) higher than the official unemployment rate, with a maximum of 2.0 ppts higher between 1996 and 2018. This paper further quantifies the contributions to businesscycle fluctuations in the unemployment rate from job separation, job finding, and participation. Correcting for misclassification changes previous studies' results about the contributions of these transition probabilities: job separation accounts for more of the unemployment fluctuations, while participation accounts for fewer. The methodology I propose can be applied to any other labor force survey in which labor force status is observed for three periods.
\end{abstract}

JEL Classification Numbers: E24, E32, J32, J6

Keywords: Gross Worker Flows, Current Population Survey, Classification Errors, Unemployment Author's E-Mail Address: ishibata@imf.org

\footnotetext{
${ }^{1}$ This paper has previously been circulated as "Reassessing Classification Errors in the Analysis of Labor Market Dynamics." I would like to thank Robert Shimer, Steven Davis, and Loukas Karabarbounis for their great advice and support. I would also like to thank Ali Alichi, Seth Blumberg, Daisuke Fujii, Kenichi Nagasawa, John Nash, Inci Otker, and seminar participants at the University of Chicago and the International Monetary Fund Western Hemisphere Department for their invaluable suggestions. All remaining errors are my own.
} 


\section{Introduction}

"Response errors are problem in all research utilizing sample surveys. Significant rates of response error have substantial implications for research on labor market dynamics, since they result in spurious transitions between labor market states." - James M. Poterba and Lawrence H. Summers (1995)"

Accuracy in measuring the labor market is critical for policymakers. In the United States, the Federal Reserve needs to adequately measure slack in the labor market to make monetary policy decisions. Congress considers labor market conditions in implementing fiscal stimulus, training programs, and unemployment insurance policies. However, classification error - in which survey respondents misreport their true labor force status - in the U.S. Current Population Survey (CPS) is found to be substantial (e.g. Abowd and Zellner, 1985 and Poterba and Summers, 1986).

In this paper, I propose a latent variable model to statistically infer workers' true labor force status from multiple periods of reported employment status without relying on any external source in a similar spirit to Biemer and Bushery (2000), Feng and Hu (2013), Hu (2008) and $\mathrm{Hu}$ (2017). I then study whether U.S. labor market dynamics change once measurement error is corrected. In particular, I examine whether correcting for measurement error would change the historical unemployment rate (stock analysis) and the degrees of the contributions of various labor market flows to the unemployment fluctuations (flow analysis).

This paper finds that correcting for classification errors changes the U.S. labor market dynamics. Once measurement error is corrected, the U.S. unemployment rate is on average 0.8 percentage points higher than the official unemployment rate. For the flow analysis, measurement error corrections proposed in this paper still support, but moderate, the previous literature's conclusion regarding the contributions of variabilities across different labor market flows to the cyclical fluctuations in the unemployment rate. I find that the job finding probability plays a more important role in explaining unemployment fluctuations ("outs of unemployment") than the job separation probability does ("ins to unemployment"), but the job separation margin matters more than previously thought. The contributions of the job separation probability to the fluctua- 
tions of unemployment rate ("Ins") increase to around 30 percent relative to the previous estimate of 20 percent (Shimer, 2012). In sum, "outs" still win, but "ins" also matter. The results also suggest that the importance of the participation margin (i.e. movement in and out of the labor force) in explaining the fluctuations in unemployment is much less than previously estimatedaround 10 percent in this paper vs previous estimates of 20 to 30 percent in Elsby, Hobijn and Sahin, (2015). Therefore, policymakers should also pay closer attention to the job separation margin in mitigating the fluctuations in the unemployment rate, but less to the nonparticipation margin.

This paper also compares different methods to correct measurement errors and their implications for analyzing the labor market flows. Specifically, I compare how the unemployment rate changes depending on different error correction methods including the ones based on reinterview surveys (i.e. Abowd and Zellner, 1985 and Poterba and Summers, 1986) and a statistcal method from Feng and $\mathrm{Hu}$ (2013). The unemployment rate is higher once measurement error is corrected by any of these methods. To quantify the contributions to business-cycle fluctuations in the unemployment rate from job separation, job finding, and participation (flow analysis), I adjust flow probabilities based on these alternative error correction probabilities. However, I find that some classification error adjustment methods (e.g. Poterba and Summers, 1986, and Feng and Hu, 2013) could imply flow probabilities occasionally exceeding 100 percent while others being below zero percent. I show that the latent variable approach with the first order Markov process assumption for the true labor force status proposed in this paper would restrict the probabilities in a reasonable range (between 0 and 100) and thus can be used for the flow analysis (e.g. Shimer, 2012 and Elsby, Hobijn and Sahin, 2015). I also verify the robustness of the first order Markov assumption for the underlying true labor market transition. Even if the data generating process does not follow the first order Markov process, the first order Markov process can generally capture the underlying transitions for three months of labor market transitions.

The rest of the paper is organized as follows. Section 2 reviews different methods to correct measurement errors. Section 3 presents a proposed latent variable model to correct measurement errors, and its identification. Section 4 describes the Current Population Survey data which I use 
to estimate my model. Section 5 presents the main results of the model and compare the results across different methods of correcting measure errors in estimating the true unemployment and flow probabilities. Section 6 studies the role of a job finding, a job separation, or a labor force participation margin in explaining unemployment fluctuations. Section 7 concludes.

\section{Different Methods of Correcting Measurement Errors}

The traditional approach to correcting reporting inaccuracies is for the CPS to reinterview respondents to check their previous labor force status. Abowd and Zellner (1985) and Poterba and Summers (1986), for instance, use the CPS reinterview surveys to calculate the classification error probabilities by comparing the reported labor force status in the original CPS survey with those in the reinterview survey. Table 1 and Table 2 show the reporting error matrix in Abowd and Zellner (1985) and Poterba and Summers (1986), respectively. The $(i, j)$ th entry of the matrix shows the probability of reporting a labor force status $j$ given that the "true" labor force status is $i$. The off-diagonal elements show the classification error probabilities, and they are substantial. For example, a large fraction of unemployed people (based on the re-interview survey) misreported as being nonparticipants in the original interview.

While this reinterview survey is considered one of the most reliable ways to identify the extent of misclassification in the CPS, there are several caveats to this approach. First, reinterview surveys are not readily accessible to outside researchers. To my knowledge, the only available reporing error matrices based on the reinterview surveys are from more than 30 years ago, published in Abowd and Zellner (1985) and Poterba and Summers (1986). More importantly, the reinterview surveys themselves are also subject to potential biases and classification errors. For instance, the reinterviews are generally conducted for a small subsample and via telephone while the original surveys were conducted in person. The time lag between the original interview and the reinterview could be another source of potential reporting errors. Moreover, it is known that workers' responses in the reinterviews often differ depending on whether the respondents have access to their original survey responses (Poterba and Summers, 1986). 
Table 1: Abowd \& Zellner (1985) Reinterview Data: 1977:1-1982:4

\begin{tabular}{|c|c|c|c|}
\hline (In percentage points) & \multirow{2}{*}{\multicolumn{3}{|c|}{$\begin{array}{c}\text { (Reported) Labor Force Status } \\
\text { In Original Interview }\end{array}$}} \\
\hline (True) Labor Force Status & & & \\
\hline Determined on Reinterview & Employed & Unemployed & Nonparticipation \\
\hline Employed & 98.78 & 0.19 & 1.03 \\
\hline Unemployed & 1.91 & 88.57 & 9.52 \\
\hline Nonparticipation & .50 & .29 & 99.21 \\
\hline
\end{tabular}

Table 2: Poterba \& Summers (1986) Reinterview Data: 1977:1-1982:4

\begin{tabular}{|c|c|c|c|}
\cline { 3 - 4 } \multicolumn{1}{c|}{$($ In percentage points) } & \multicolumn{3}{c|}{$\begin{array}{c}\text { Reported) Labor Force Status } \\
\text { In Original Interview }\end{array}$} \\
\cline { 3 - 4 } (True) Labor Force Status & \multicolumn{3}{|c|}{ Determined on Reinterview } \\
\cline { 3 - 4 } & Employed & Unemployed & Nonparticipation \\
\hline Employed & 97.74 & 0.54 & 1.72 \\
\hline Unemployed & 3.78 & 84.76 & 11.46 \\
\hline Nonparticipation & 1.16 & 0.64 & 98.2 \\
\hline
\end{tabular}

An alternative approach for correcting classification errors is to apply a latent variable model to statistically infer workers' true labor force status from multiple periods of reported employment status without relying on any external source (e.g Feng and Hu, 2013, Hu, 2008, and $\mathrm{Hu}, 2017)$. The intuition behind this approach is that some irregularities in the labor market transitions inform possible underlying measurement errors of labor market data. For instance, if a person reports as being unemployed in the first month (U), moving out of the labor force (O) in the second month, and moving back to unemployment (U) in the third month, there is some chance that the true labor status in the second month is also unemployment (U) instead of nonparticipation $(\mathrm{O})$. Imposing some statistical assumptions on the true underlying labor market transitions and how respondents misreport their true labor force (reporting error probabilities), the labor market histories would be able to inform possible magnitudes of measurement error. For instance, Feng and $\mathrm{Hu}$ (2013) use a variant of latent variable models to estimate the reporting errors based on three months of data (i.e. first, second, and ninth months of labor force states in the CPS) (Table 3). They show that the reported official unemployment rate is underestimated by approximately 2.1 percentage points between 1996 and 2011. The current paper follows this second latent variable approach to correcting misclassification but differs in one of the assumptions-a first-order Markov process for the labor market transition. 
Table 3: Feng and Hu (2013) estimates of classification errors: January 1996-December 2009

\begin{tabular}{|c|c|c|c|}
\cline { 2 - 4 } True Labor Force Status & \multicolumn{3}{|c|}{ Reported Labor Force Status } \\
\cline { 2 - 4 } & Employed & Unemployed & Nonparticipation \\
\hline Employed & 97.9 & 0.6 & 1.5 \\
\hline Unemployed & 17.3 & 62.5 & 20.2 \\
\hline Nonparticipation & 2.9 & 0.2 & 96.9 \\
\hline
\end{tabular}

Source: Feng and Hu (2013, Table 1)

\section{Model and Identification}

This section presents a hidden Markov model (HMM), a latent variable approach, to estimate measurement errors in the Current Population Survey. The identification results are borrowed from $\mathrm{Hu}$ (2008), Feng and $\mathrm{Hu}$ (2013), and Hu (2017). Unlike Feng and Hu (2013), I assume that the true labor force status (LFS) transition dynamics follow the first order Markov process.

Let $Y_{t}$ be the reported labor force status in month $t$ where $Y_{t}$ is either 1 (employed), 2 (unemployed) or 3 (nonparticipation). Let $\tilde{Y}_{t}$ be the corresponding true labor force status in $t=1, \ldots, \bar{T}$. I first make the following assumption to relate the reported labor force status with the underlying true labor force status.

Assumption 1 (Conditional Independence): The probability distribution of the misclassification errors only depend on the true labor force status in the current period:

$$
\operatorname{Pr}\left(Y_{t} \mid \tilde{Y}_{t}, Y_{\tau \neq t}, \tilde{Y}_{\tau \neq t}\right)=\operatorname{Pr}\left(Y_{t} \mid \tilde{Y}_{t}\right)
$$

for all $t$ and with $\tau \neq t$.

I denote this $3 \times 3$ reporting error (misclassification) probability matrix as $B$ with $(i, j)$ th entry being $b_{i j}=\operatorname{Pr}\left(Y_{t}=j \mid \tilde{Y}_{t}=i\right)$ where $i, j \in\{1,2,3\}$ denotes employed $(1=E)$, unemployed $(2=U)$, and nonparticipant $(3=O)$, respectively. This assumption has been widely accepted in the literature including the studies that use the reinterview survey (e.g. Abowd and Zellner, 1985, and Poterba and Summers, 1986). Meyer (1988) compares Assumption 1 with an alternative specification that estimates the probability of true labor force status conditional on the reported labor force status, (i.e., $\left.\operatorname{Pr}\left(\tilde{Y}_{t} \mid Y_{t}\right)\right)$. He argues that this alternative specification is less plausible 
as it would imply that a worker reported as employment and transitioned to unemployed would have the same probability of being truly employed as an employed worker who continues to be employed. Feng and $\mathrm{Hu}$ (2013) also test other specifications of Assumption 1 including the reporting error probability also depending on i) the true labor force status in the previous period $\left(\operatorname{Pr}\left(Y_{t} \mid \tilde{Y}_{t}, Y_{\tau \neq t}, \tilde{Y}_{\tau \neq t}\right)=\operatorname{Pr}\left(Y_{t} \mid \tilde{Y}_{t}, \tilde{Y}_{t-1}\right)\right.$, ii) reported labor force status in the previous period $\left(\operatorname{Pr}\left(Y_{t} \mid \tilde{Y}_{t}, Y_{\tau \neq t}, \tilde{Y}_{\tau \neq t}\right)=\operatorname{Pr}\left(Y_{t} \mid \tilde{Y}_{t}, Y_{t-1}\right)\right)$ and iii) both true and reported labor force states in the previous period $\left(\operatorname{Pr}\left(Y_{t} \mid \tilde{Y}_{t}, Y_{\tau \neq t}, \tilde{Y}_{\tau \neq t}\right)=\operatorname{Pr}\left(Y_{t} \mid \tilde{Y}_{t}, \tilde{Y}_{t-1}, Y_{t-1}\right)\right)$ and show that the estimations are generally robust to these alternative specifications.

Assumption 1 allows one to express the probability of observing labor force status history $\operatorname{Pr}\left(Y_{t+1}, Y_{t}, Y_{t-1}\right)$ as follows:

$$
\operatorname{Pr}\left(Y_{t+1}, Y_{t}, Y_{t-1}\right)=\sum_{\tilde{Y}_{t+1}} \sum_{\tilde{Y}_{t}} \sum_{\tilde{Y}_{t-1}} \operatorname{Pr}\left(Y_{t+1} \mid \tilde{Y}_{t+1}\right) \operatorname{Pr}\left(Y_{t} \mid \tilde{Y}_{t}\right) \operatorname{Pr}\left(Y_{t-1} \mid \tilde{Y}_{t-1}\right) \operatorname{Pr}\left(\tilde{Y}_{t+1}, \tilde{Y}_{t}, \tilde{Y}_{t-1}\right)
$$

Assumption 2 (First Order Markov Assumption): The true labor force status $\tilde{Y}_{t}$ follows a first order Markov process.

$$
\operatorname{Pr}\left(\tilde{Y}_{t+1} \mid \tilde{Y}_{t}, \tilde{Y}_{t-1}, \ldots \tilde{Y}_{1}\right)=\operatorname{Pr}\left(\tilde{Y}_{t+1} \mid \tilde{Y}_{t}\right)
$$

for all $t$.

I denote the probability of transitioning from true labor force status $i$ to $j$ as $a_{i j}=\operatorname{Pr}\left(\tilde{Y}_{t+1}=\right.$ $\left.j \mid \tilde{Y}_{t}=i\right)$ for $i, j \in\{1,2,3\}$, and let $A$ be a $3 \times 3$ matrix with its $(i, j)$ th entry being $a_{i j}$. Feng and $\mathrm{Hu}$ (2013) make a weaker assumption that the true labor force status nine months ago has no additional predicting power for this period's true labor force status once conditioned on this period's true labor force status: $\operatorname{Pr}\left(\tilde{Y}_{t+1} \mid \tilde{Y}_{t}, \tilde{Y}_{t-9}\right)=\operatorname{Pr}\left(\tilde{Y}_{t+1} \mid \tilde{Y}_{t}\right)$. I will return to the costs and benefits of this assumption in the next section.

Using Assumption 2, equation (1) can be simplified to

$$
\operatorname{Pr}\left(Y_{t+1}, Y_{t}, Y_{t-1}\right)=\sum_{\tilde{Y}_{t}} \operatorname{Pr}\left(Y_{t+1} \mid \tilde{Y}_{t}\right) \operatorname{Pr}\left(Y_{t} \mid \tilde{Y}_{t}\right) \operatorname{Pr}\left(\tilde{Y}_{t}, Y_{t-1}\right)
$$


By integrating out $\tilde{Y}_{t+1}$, we obtain

$$
\operatorname{Pr}\left(Y_{t}, Y_{t-1}\right)=\sum_{\tilde{Y}_{t}} \operatorname{Pr}\left(Y_{t} \mid \tilde{Y}_{t}\right) \operatorname{Pr}\left(\tilde{Y}_{t}, Y_{t-1}\right)
$$

Now we can express equations (2) and (3) in matrix form. First, define $\Phi_{Y_{t} \mid \tilde{Y}_{t}}$ to be a transpose of the measurement error matrix $B$ and $\beta_{\cdot i} \equiv\left(\begin{array}{ccc}b_{1 i} & b_{2 i} & b_{3 i}\end{array}\right)$ for $i \in\{1,2,3\}$.

$$
\begin{gathered}
\Phi_{Y_{t} \mid \tilde{Y}_{t}} \equiv\left[\begin{array}{ccc}
\operatorname{Pr}\left(Y_{t}=1 \mid \tilde{Y}_{t}=1\right) & \operatorname{Pr}\left(Y_{t}=1 \mid \tilde{Y}_{t}=2\right) & \operatorname{Pr}\left(Y_{t}=1 \mid \tilde{Y}_{t}=3\right) \\
\operatorname{Pr}\left(Y_{t}=2 \mid \tilde{Y}_{t}=1\right) & \operatorname{Pr}\left(Y_{t}=2 \mid \tilde{Y}_{t}=2\right) & \operatorname{Pr}\left(Y_{t}=2 \mid \tilde{Y}_{t}=3\right) \\
\operatorname{Pr}\left(Y_{t}=3 \mid \tilde{Y}_{t}=1\right) & \operatorname{Pr}\left(Y_{t}=3 \mid \tilde{Y}_{t}=2\right) & \operatorname{Pr}\left(Y_{t}=3 \mid \tilde{Y}_{t}=3\right)
\end{array}\right] \\
=B^{T}=\left[\begin{array}{ccc}
b_{11} & b_{21} & b_{31} \\
b_{12} & b_{22} & b_{32} \\
b_{13} & b_{23} & b_{33}
\end{array}\right] \equiv\left[\begin{array}{c}
\beta_{\cdot 1} \\
\beta_{\cdot 2} \\
\beta_{\cdot 3}
\end{array}\right]
\end{gathered}
$$

Each column of $B^{T}$, vector $\beta_{\cdot i}$, captures the probability of a worker reporting a different labor force status given his or her true labor force status $i$. Similarly, define $\alpha_{i}$. $\equiv\left[\begin{array}{lll}a_{i 1} & a_{i 2} & a_{i 3}\end{array}\right]$ for $i=1,2,3$ so that the transition matrix of underlying labor force status, $A$, can be expressed as:

$$
A=\left[\begin{array}{ccc}
a_{11} & a_{12} & a_{13} \\
a_{21} & a_{22} & a_{23} \\
a_{31} & a_{32} & a_{33}
\end{array}\right] \equiv\left[\begin{array}{c}
\alpha_{1} \\
\alpha_{2} \\
\alpha_{3}
\end{array}\right]
$$

$\alpha_{i}$. expresses the probability that a worker transitions from true labor force status $i$ to different true labor force states. Then, we can express the following diagonal matrix, $D_{1 \mid \tilde{Y}_{t}}$ using $\alpha$ and $\beta$ as:

$$
D_{1 \mid \tilde{Y}_{t}} \equiv\left[\begin{array}{ccc}
\operatorname{Pr}\left(Y_{t+1}=1 \mid \tilde{Y}_{t}=1\right) & 0 & 0 \\
0 & \operatorname{Pr}\left(Y_{t+1}=1 \mid \tilde{Y}_{t}=2\right) & 0 \\
0 & 0 & \operatorname{Pr}\left(Y_{t+1}=1 \mid \tilde{Y}_{t}=3\right)
\end{array}\right]
$$




$$
=\left[\begin{array}{ccc}
\alpha_{1} \cdot \beta \cdot 1 & 0 & 0 \\
0 & \alpha_{2 \cdot} \cdot \beta_{1} & 0 \\
0 & 0 & \alpha_{3 \cdot} \cdot \beta_{\cdot 1}
\end{array}\right]
$$

Also define the probability of the true labor force status as $\pi_{i} \equiv \operatorname{Pr}\left(\tilde{Y}_{t}=i\right)$ and $\Pi \equiv$ $\left(\begin{array}{lll}\pi_{1} & \pi_{2} & \pi_{3}\end{array}\right)$. Define a matrix

$$
\begin{aligned}
\Phi_{\tilde{Y}_{t}, Y_{t-1}} & \equiv\left[\begin{array}{lll}
\operatorname{Pr}\left(\tilde{Y}_{t}=1, Y_{t-1}=1\right) & \operatorname{Pr}\left(\tilde{Y}_{t}=1, Y_{t-1}=2\right) & \operatorname{Pr}\left(\tilde{Y}_{t}=1, Y_{t-1}=3\right) \\
\operatorname{Pr}\left(\tilde{Y}_{t}=2, Y_{t-1}=1\right) & \operatorname{Pr}\left(\tilde{Y}_{t}=2, Y_{t-1}=2\right) & \operatorname{Pr}\left(\tilde{Y}_{t}=2, Y_{t-1}=3\right) \\
\operatorname{Pr}\left(\tilde{Y}_{t}=3, Y_{t-1}=1\right) & \operatorname{Pr}\left(\tilde{Y}_{t}=3, Y_{t-1}=2\right) & \operatorname{Pr}\left(\tilde{Y}_{t}=3, Y_{t-1}=3\right)
\end{array}\right] \\
& =A^{T} \operatorname{diag}(\Pi) B
\end{aligned}
$$

Similarly, define the distribution of $Y_{t}$ and $Y_{t-1}$ as:

$$
\begin{aligned}
\Phi_{Y_{t}, Y_{t-1}} & \equiv\left[\begin{array}{ccc}
\operatorname{Pr}\left(Y_{t}=1, Y_{t-1}=1\right) & \operatorname{Pr}\left(Y_{t}=1, Y_{t-1}=2\right) & \operatorname{Pr}\left(Y_{t}=1, Y_{t-1}=3\right) \\
\operatorname{Pr}\left(Y_{t}=2, Y_{t-1}=1\right) & \operatorname{Pr}\left(Y_{t}=2, Y_{t-1}=2\right) & \operatorname{Pr}\left(Y_{t}=2, Y_{t-1}=3\right) \\
\operatorname{Pr}\left(Y_{t}=3, Y_{t-1}=1\right) & \operatorname{Pr}\left(Y_{t}=3, Y_{t-1}=2\right) & \operatorname{Pr}\left(Y_{t}=3, Y_{t-1}=3\right)
\end{array}\right] \\
& =\Phi_{Y_{t} \mid \tilde{Y}_{t}}^{\Phi_{\tilde{Y}_{t}, Y_{t-1}}} \\
& \underbrace{}_{\Phi_{Y_{t} \mid \tilde{Y}_{t}}^{B^{T}} \underbrace{A^{T}}_{\Phi_{\tilde{Y}_{t}, Y_{t-1}}^{A^{T} d i a g}(\Pi) B}}
\end{aligned}
$$

The distribution of $Y_{t+1}=1, Y_{t}, Y_{t-1}$ can also be expressed as:

$$
\begin{aligned}
\Phi_{1, Y_{t}, Y_{t-1}} & \equiv\left[\begin{array}{ccc}
\phi_{111} & \phi_{211} & \phi_{311} \\
\phi_{121} & \phi_{221} & \phi_{321} \\
\phi_{131} & \phi_{231} & \phi_{333}
\end{array}\right] \\
& =\Phi_{Y_{t} \mid \tilde{Y}_{t}} D_{1 \mid \tilde{Y}_{t}} \Phi_{\tilde{Y}_{t} Y_{t-1}} \\
& =\underbrace{B^{T}}_{\Phi_{Y_{t} \mid \tilde{Y}_{t}}} D_{1 \mid \tilde{Y}_{t}} \underbrace{}_{\Phi_{\tilde{Y}_{t} Y_{t-1}}^{A^{T} \operatorname{diag}(\Pi) B}}
\end{aligned}
$$

where $\phi_{i j 1} \equiv \operatorname{Pr}\left(Y_{t+1}=1, Y_{t}=j, Y_{t-1}=i\right)$ for $i, j \in\{1,2,3\}$.

Assumption 3: The distributions of the current reported labor force status conditional 
on different reported labor force status in the previous month are linearly independent. i.e. $\operatorname{Pr}\left(Y_{t} \mid Y_{t-1}=1\right)$ is not a linear combination of $\operatorname{Pr}\left(Y_{t} \mid Y_{t-1}=2\right)$ and $\operatorname{Pr}\left(Y_{t} \mid Y_{t-1}=3\right)$ for all $Y_{t}$.

Assumption 3 implies that $\Phi_{Y_{t}, Y_{t-1}}$ is invertible. This together with equation (4) implies that $\Phi_{Y_{t} \mid \tilde{Y}_{t}}=B^{T}$ and $\Phi_{\tilde{Y}_{t}, Y_{t-1}}=A^{T} \operatorname{diag}(\Pi) B$ are invertible. We can now eliminate $\Phi_{\tilde{Y}_{t}, Y_{t-1}}$ from equation (4) and (5).

$$
\begin{aligned}
\Phi_{1, Y_{t}, Y_{t-1}} & \equiv \Phi_{Y_{t} \mid \tilde{Y}_{t}} D_{1 \mid \tilde{Y}_{t}}\left(\Phi_{\tilde{Y}_{t}, Y_{t-1}}\right) \\
& =\Phi_{Y_{t} \mid \tilde{Y}_{t}} D_{1 \mid \tilde{Y}_{t}}\left(\Phi_{Y_{t} \mid \tilde{Y}_{t}}^{-1} \Phi_{Y_{t}, Y_{t-1}}\right) \\
\Phi_{1, Y_{t}, Y_{t-1}} \Phi_{Y_{t}, Y_{t-1}}^{-1} & =\Phi_{Y_{t} \mid \tilde{Y}_{t}} D_{1 \mid \tilde{Y}_{t}}\left(\Phi_{Y_{t} \mid \tilde{Y}_{t}}^{-1}\right) \\
& =B^{T} D_{1 \mid \tilde{Y}_{t}}\left(B^{T}\right)^{-1}
\end{aligned}
$$

Assumption 4: A different true labor force status in this month leads to a different probability of reported labor force status in the next month and the distribution of the reported labor force status in the next month conditional on true labor force status in this month is linearly independent. i.e. $\operatorname{Pr}\left(Y_{t+1}=k \mid \tilde{Y}_{t}=i\right)$ is different for $k, i \in\{1,2,3\}$ and $\operatorname{Pr}\left(Y_{t} \mid \tilde{Y}_{t-1}=1\right)$ is not a linear combination of $\operatorname{Pr}\left(Y_{t} \mid \tilde{Y}_{t-1}=2\right)$ and $\operatorname{Pr}\left(Y_{t} \mid \tilde{Y}_{t-1}=3\right)$ for all $Y_{t}$.

This is equivalent to the condition that $A B$ is invertible and that each item in $D_{k \mid \tilde{Y}_{t}}$ for

$k \in\{1,2,3\}$ are distinct. This condition also implies that the eigenvalues of $\Phi_{1, Y_{t}, Y_{t-1}} \Phi_{Y_{t}, Y_{t-1}}^{-1}$ in equation (7) are distinct. The uniqueness of the eigenvectors is guaranteed by the distinct eigenvalues.

\section{Assumption 5 (Ordering):}

Individuals are more likely to report true labor force status than to report any other possible labor force status.

$$
\operatorname{Pr}\left(Y_{t}=i \mid \tilde{Y}_{t}=i\right)>\operatorname{Pr}\left(Y_{t}=i \mid \tilde{Y}_{t}=j\right) \quad \forall i \neq j \text { for } i, j \in\{1,2,3\}
$$

This ordering assumption is consistent with the reinterview survey results from Poterba and 
Summers (1986) and Abowd and Zellner (1985). Without this ordering assumption, we can only identify up-to permutation or label swapping. This ordering assumption pins down the latent variable, such as employment, unemployment, and nonparticipation.

We can also obtain the probability of being in true labor force status $i$ in $t, \pi_{i} \equiv \operatorname{Pr}\left(\tilde{Y}_{t}=i\right)$, as follows:

$$
\left[\begin{array}{c}
\operatorname{Pr}\left(Y_{t}=1\right) \\
\operatorname{Pr}\left(Y_{t}=2\right) \\
\operatorname{Pr}\left(Y_{t}=3\right)
\end{array}\right]=\underbrace{\Phi_{Y_{t} \mid \tilde{Y}_{t}}}_{B^{T}}\left[\begin{array}{c}
\operatorname{Pr}\left(\tilde{Y}_{t}=1\right) \\
\operatorname{Pr}\left(\tilde{Y}_{t}=2\right) \\
\operatorname{Pr}\left(\tilde{Y}_{t}=3\right)
\end{array}\right]
$$

Since $B^{T}$ is assumed to be invertible, we can identify the distribution of the true labor force status $\left(\begin{array}{lll}\pi_{1} & \pi_{2} & \pi_{3}\end{array}\right)$ by inverting $\Phi_{Y_{t} \mid \tilde{Y}_{t}}$ :

$$
\left[\begin{array}{c}
\operatorname{Pr}\left(\tilde{Y}_{t}=1\right) \\
\operatorname{Pr}\left(\tilde{Y}_{t}=2\right) \\
\operatorname{Pr}\left(\tilde{Y}_{t}=3\right)
\end{array}\right]=\left(\Phi_{Y_{t} \mid \tilde{Y}_{t}}\right)^{-1}\left[\begin{array}{c}
\operatorname{Pr}\left(Y_{t}=1\right) \\
\operatorname{Pr}\left(Y_{t}=2\right) \\
\operatorname{Pr}\left(Y_{t}=3\right)
\end{array}\right]
$$

Lastly, from equation (4), we can obtain the transition matrix of true labor force status, $A$ :

$$
A^{T}=\left(B^{T}\right)^{-1} \Phi_{Y_{t}, Y_{t-1}} B^{-1} \operatorname{diag}(\Pi)^{-1}
$$

This formula is similar to the misclassification adjustment method to flows in Poterba and Summers (1986) shown later in equation (12). The difference is that equation (9) directly adjusts the observed probabilities instead of flow levels as in Poterba and Summers (1986). Based on the assumptions 1-5 and following Feng and $\mathrm{Hu}$ (2013), $\mathrm{Hu}$ (2008), and $\mathrm{Hu}$ (2017), the model is identified. We can first estimate the reporting error matrix $B$ by using the eigenvalue-eigenvector decomposition in equation (7). We then can recover the distribution of true labor force status, $\Pi$, using equation (8), and finally the transition matrix for true labor force status, $A$, using equation (9).

The eigenvalue-eigenvector decomposition shown above and introduced by Feng and $\mathrm{Hu}$ (2013) and $\mathrm{Hu}(2008)$ guarantees global identification results. In practice, the maximum likeli- 
hood estimation of the hidden Markov model (HMM), which only guarantees a local maximum, produced the results in line with those based on eigenvalue-eigenvector decomposition method. The results in eigenvalue-eigenvector decomposition method described above only uses a subset of the sample-for which the labor force status in the third month is employed (i.e. $\left.Y_{t+1}=1\right)$ and the estimates change depending on which subsample is used. On the other hand, the maximum likelihood estimation which only guarantees a local maximum uses the entire sample. Both are generally similar but I have used the maximum likelihood estimation (MLE) procedure. With the MLE, the adjustment procedure based on the error matrix in equation (9) becomes unnecessary because the transition probabilities for the true labor force status and the reporting error matrix are jointly estimated. Appendix 1 provides details of the maximum likelihood estimation (MLE) and compare the misclassification matrices based on the eigenvalue-eigenvector decomposition method and the MLE. Appendix 2 compares the global identification result by Feng and $\mathrm{Hu}$ (2013) and $\mathrm{Hu}$ (2008) and the local identification result by Allman, Matias, and Rhodes (2009). The next section discusses the costs and benefits of the first order Markov assumption.

\subsection{Costs and Benefits of First Order Markov Assumption}

A natural and primary way of analyzing aggregate labor market dynamics at business cycle frequencies has been looking at the gross flows of workers between two consecutive months, which is fully consistent with the first order Markov assumption for labor flows (e.g. Abowd and Zellner 1985, Poterba and Summers 1986, Blanchard and Diamond 1990, Mortensen and Pissarides 1994, and Shimer 2005). Aggregate labor market indicators, such as the unemployment rate and the employment rate, are stocks at a point in time. The evolutions of these stock variables can be analyzed through the gross flows in and out of these stocks or movements of workers between employment, unemployment, and nonparticipant, over two consecutive months. For instance, Singh and Rao (1995) stress the importance of studying the gross flows between the two months as follows:

"Gross labor flows are important to researchers and policy analysts for understanding labor market dynamics... The monthly stocks tell us only what net changes, if any, 
there has been in the levels of employment, unemployment, and the counts of persons outside the labor force. To determine how much "turbulence" lies behind the net changes, one must go ... see how many persons are flowing back and forth between groups regardless of their size (e.g., into and out of labor force and between employed and unemployed within the labor force). Especially for policy purposes, it is useful to know answers to questions like (a) what proportion of persons who are unemployed in a given month are also jobless in the following month, what proportion find jobs, and what proportion get discouraged and leave the labor force? and (b) How much of the increase is due to persons losing or leaving jobs and how much is due to persons not in the labor force starting to look for jobs?" (p. 478)

Calculating the proportion of workers in one labor force status, $i$, in one month who move to another labor force status, $j$, in the next month is equivalent to calculating a first order Markov transition probability (i.e. $\operatorname{Pr}\left(Y_{t+1}=j \mid Y_{t}=i\right)$ for $\left.i, j \in\{E, U, O\}\right)$ using the data for the two consecutive months. For instance, calculating the proportion of the currently unemployed persons in a given month who would find a job in the following month is a job finding probability.

In addition, the first order Markov assumption makes it possible to compare the results of this paper with those in the previous literature (e.g. Shimer 2012, and Elsby, Hobijn and Sahin 2015). Most macro labor literature, both theoretical and empirical, has explicitly or implicitly used the first order Markov assumption for labor market transitions (e.g. Blanchard and Diamond 1990, Mortensen and Pissarides 1994, Shimer 2005, and Shimer 2008). For instance, Shimer (2012) has studied the contributions of transitions between different labor force status to the fluctuations of unemployment at business cycle frequencies. He finds that the job finding probability (transition out from unemployment to employment) plays a more important role than the job separation probability (transition into unemployment from employment). In short, "Outs" wins. Elsby, Hobijn, and Sahin (2015) show that the partcipation margin (movement in and out of the labor force) also accounts for a significant fraction of the unemployment fluctuation. The results in this paper argue that the proposed misclassificaiton adjustment does not overturn the results but mutes the results in the previous literature. 
Another benefit of imposing the first order Markov process assumption for workers' transitions restrict underlying transition probabilities remain within a reasonable range (i.e. between 0 and 100 percent). As I show later, the reporting errors estimated in Feng and $\mathrm{Hu}$ (2013) imply adjusted transition probabilities occassionally below 0 or above 100 percent. Certainly, one could truncate negative values to zero and any values greater than one to one. However, even if one of the elements in the transition matrix is truncated to one (i.e. if one of the states in the transition matrix is an absorbing state), the long-run implications of the first order Markov transition matrix will be that workers will be in that absorbing state. The average duration of being in a particular labor force status is also undefined.

Lastly, another reason for choosing the first order Markov process assumption for workers' transition instead of using Feng and Hu's assumption (2013) for labor market transition is to avoid another source of errors (i.e. attrition) by linking the CPS over a 9 month period. While the fraction of individuals who can be matched over first four consecutive months are relatively high (around 90 percent of eligible rotation groups), the matching rate declines for the 12 th monthly survey (approximately 65 percent). This results in additional source of potential errors.

However, one major cost of the first order Markov process assumption for workers' transitions is that as shown in the micro labor literature, the data at the individual level are inconsistent with the first order Markov process. Labor market transitions are indeed duration dependent and heterogeneous. A prominent example is that a long-term unemployed person has a lower chance of landing on a job than a recently unemployed person. However, for a short period of time, the first-order Markov approximation to the labor market transition rates is innocuous. As a robustness check, I test the validity of the first order Markov assumption (Assumption 2) in Appendix and show that it is genrally robust. In this exercise, I assume that the data generating process is a second order Markov process and estimate the model using the simulated data. The distribution of true labor force history as well as measurement error matrix can generally be recovered. I also allow the transition probabilities for the labor force states to vary over time while keeping the reporting error matrices fixed as in the previous literature. 


\section{Data}

To estimate the latent Markov model, I use the Current Population Survey (CPS) from January 1996 to September 2018. This choice of time periods is prompted by 1) a CPS redesign in 1994 and 2) the similar time coverage as Feng and $\mathrm{Hu}$ (2013). In each month, CPS interviews approximately 60,000 households and 100,000 to 150,000 individuals based on physical address and contains information regarding workers' employment status, industries, and demographics (e.g. sex, age, race, geographical locations, and education). Households are interviewed for four consecutive months, rotated out for the next eight months before being interviewed again for the final four months. This structure allows researchers to track workers' employment status for a maximum of 8 months over the period of 16 months. I use the three months of workers' employment status to estimate a latent Markov model.

As in Shimer (2012), I follow the algorithm in Madrian and Lefgren (2000) to match CPS monthly files for three consecutive months. Specifically, I match two individuals in the two monthly files in period $t$ and period $t+k$ (for $k \in\{1,2\}$ ) based on individuals' household identifier, household replacement number (which identifies whether the initial household has been replaced), personal identifier, sex, age, and race. Age is allowed to differ by increment of 1 between consecutive months.

Due to its survey design, each CPS monthly file contains eight rotation group where rotation group is defined by the number of months in the survey. In month $t$, only individuals in rotation

group 1 (those who just entered into the survey) are eligible to be matched for the eight months over the length of next 16 months. This limits the eligible group to approximately one eighth of the total observations in each monthly file. For three months of labor force history data, about one-half of the sample in the initial survey can be matched (i.e. rotation groups $=1,2,5$, and 6). Nonetheless, some of these eligible individuals cannot be matched for various reasons such as simple attrition and coding errors.

Matching individuals over time expand the research scope for panel data analysis. Nevertheless, cross-sectional statistics implied by the matched individuals do not necessarily line up with the aggregate cross-sectional statistics because we can only match a subsample of the individuals 
in the survey. If the matching attrition is not completely at random and independent of any demographic characteristics, we can simply scale up the weights by the ratio of the total number of sample in the original survey to the number of matched sample. However, attrition is often not random. To ensure that demographic representations in the matched sample mirror those in the original survey, I reassign the sample weights of the matched individuals by multiplying them by the inverse of matching probability conditional on the individual's demographic characteristics. Specifically, I run a logit model and calculate the predicted probability of matching conditioning on gender, age, race education level, and the initial employment status. I then multiply the original weights with the inverse of the corresponding predicted probabilities. The results are robust to the re-weighting procedure.

\section{Results}

This section first presents the estimates of the reporting matrix $B$ from the latent variable approach from the current study (HMM). I compare the unemployment rates corrected for measurement errors across different correction methods, namely Feng and $\mathrm{Hu}$ (2013) (FH), Abowd and Zellner (1985) (AZ), and Poterba and Summers (1986) (PS), and a hidden Markov model in this paper (HMM). I then calculate the adjusted transition probabilities based on the same set of error matrices from previous studies, and compare them with my estimates of transition probabilities based on the latent variable approach (HMM).

\subsection{Reporting Error Probabilities}

Table 4 compares (1) the reporting errors, (2) adjusted transition probabilities, and (3) implied average duration of unemployment, employment, and nonparticipation across different adjustment methods. The directions of the reporting errors of HMM are similar to AZ and PS. Misreporting is most severe among the unemployed workers. The unemployed workers are more likely to misreport that they are out of the labor force than employed in all four cases (HMM, FH, AZ, and PS). The reporting errors for truly employed workers and nonparticipants in HMM are very similar to those of previous studies. The reporting error probability estimates by Feng and 
Figure 1: Adjusted Unemployment Rates

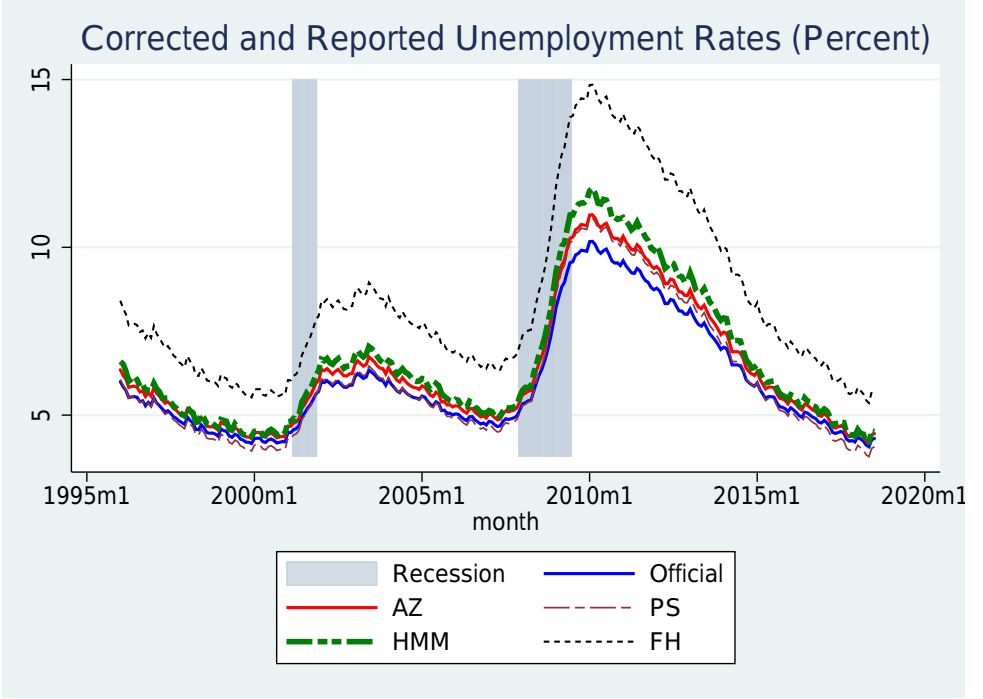

$\mathrm{Hu}$ (2013) show that close to 40 percent of the unemployed workers misreport their labor force status, which is much bigger than the estimates in HMM, AZ, and PS. In sum, HMM estimates of reporting error probabilities are between $\mathrm{FH}$ and $\mathrm{AZ} / \mathrm{PS}$ estimates and are generally similar to historical classification error estimates in Abowd and Zellner (1985) and Poterba and Summers (1986).

\section{$5.2 \quad$ Adjusted Unemployment Rates}

In this subsection, I present the adjusted unemployment rates based on various adjustment procedures. As one would predict, the HMM adjusted unemployment rate is not as high as FH but higher than unadjusted unemployment rate and FH/PS-adjusted unemployment rates. While FH-adjusted unemployment rate is on average 2.6 percentage points higher than the reported official unemployment rate, the HMM-adjusted unemployment rate is about 0.8 percentage points higher than the reported (unadjusted) unemployment rate. While it is still higher than the PS and AZ adjusted series (which are 0.24 and 0.54 higher than the reported unemployment rate on average), the HMM-adjusted unemployment rate is lower than the FH-adjusted unemployment rate. 
Table 4: Transition, Misclassification, and Duration across Models

(1) B: Misclassification Probabilities $\operatorname{Pr}(j \mid \tilde{i})=\operatorname{Pr}\left(Y_{t}=j \mid \tilde{Y}_{t}=i\right)$ for $i, j \in\{E, U, O\}$

(In percentage points)

\begin{tabular}{c|cccc}
\hline & AZ & PS & FH & HMM \\
\hline $\operatorname{Pr}(E \mid \tilde{E})$ & 98.8 & 97.7 & 97.9 & $98.7(0.06)$ \\
$\operatorname{Pr}(U \mid \tilde{E})$ & 0.2 & 0.5 & 0.6 & $0.4(0.04)$ \\
$\operatorname{Pr}(O \mid \tilde{E})$ & 1.0 & 1.7 & 1.5 & $0.9(0.04)$ \\
$\operatorname{Pr}(E \mid \tilde{U})$ & 1.9 & 3.8 & 17.3 & $7.5(0.65)$ \\
$\operatorname{Pr}(U \mid \tilde{U})$ & 88.6 & 84.8 & 62.5 & $76.4(0.98)$ \\
$\operatorname{Pr}(O \mid \tilde{U})$ & 9.5 & 11.5 & 20.2 & $16.1(0.84)$ \\
$\operatorname{Pr}(E \mid \tilde{O})$ & 0.5 & 1.2 & 2.9 & $1.4(0.09)$ \\
$\operatorname{Pr}(U \mid \tilde{O})$ & 0.3 & 0.6 & 0.2 & $1.0(0.10)$ \\
$\operatorname{Pr}(O \mid \tilde{O})$ & 99.2 & 98.2 & 96.9 & $97.6(0.13)$ \\
\hline $\operatorname{Not}$ & &
\end{tabular}

Note: Bootstrap standard errors based on 500 simulations are reported in parentheses.

(2) Average Transition Probabilities

$\operatorname{Pr}(j \mid i)=\operatorname{Pr}\left(Y_{t}=j \mid Y_{t-1}=i\right)$ for $i, j \in\{E, U, O\}$

(In percentage points)

\begin{tabular}{c|ccccc}
\hline & $\mathrm{R}^{*}$ & AZ & PS & FH & HMM \\
\hline $\operatorname{Pr}(E \mid E)$ & 95.8 & 97.2 & 98.6 & 100.5 & 98.3 \\
$\operatorname{Pr}(U \mid E)$ & 1.3 & 1.2 & 0.7 & -0.4 & 0.7 \\
$\operatorname{Pr}(O \mid E)$ & 2.9 & 1.6 & 0.6 & -0.2 & 1.0 \\
$\operatorname{Pr}(E \mid U)$ & 24.7 & 21.9 & 16.0 & 0.8 & 15.3 \\
$\operatorname{Pr}(U \mid U)$ & 50.7 & 60.3 & 69.0 & 91.4 & 77.7 \\
$\operatorname{Pr}(O \mid U)$ & 24.5 & 17.8 & 15.0 & 7.7 & 7.0 \\
$\operatorname{Pr}(E \mid O)$ & 5.3 & 2.5 & 0.3 & -1.4 & 1.4 \\
$\operatorname{Pr}(U \mid O)$ & 3.1 & 2.3 & 1.8 & 1.0 & 0.9 \\
$\operatorname{Pr}(O \mid O)$ & 91.6 & 95.1 & 97.8 & 100.4 & 97.7 \\
\hline
\end{tabular}

(3) Average Duration

\begin{tabular}{cccccc}
\multicolumn{6}{c}{ (in months) } \\
& $\mathrm{R}^{*}$ & AZ & PS & FH & HMM \\
\hline$E$ & 23.5 & 35.9 & 73.9 & -193.2 & 58.2 \\
$U$ & 2.0 & 2.5 & 3.2 & 11.7 & 4.5 \\
$O$ & 12.0 & 20.6 & 46.1 & -242.1 & 43.8 \\
\hline
\end{tabular}

$\mathrm{R}^{*}$ : reported transition probabilities without

misclassification corrections;

AZ: Abowd and Zellner (1985),

PS: Poterba and Summers (1986),

FH: Feng and $\mathrm{Hu}$ (2013),

HMM: Hidden Markov Model (This paper). 


\subsection{Adjusting Flow Probabilities}

This section shows how we adjust the flows given the error correction matrix, $B$ as shown in Poterba and Summers (1986). Let $\tilde{N}$ be the matrix of the true labor force flows where $(i, j)$ th element is total true labor force flows of workers transitioning from labor force status $i$ to $j$ for $i, j \in\{E, U, O\}$, and $N$ be corresponding reported flows in month $t$. That is

$$
\tilde{N}_{t}=\left[\begin{array}{ccc}
\tilde{E E_{t}} & \tilde{E U_{t}} & \tilde{E O_{t}} \\
\tilde{U E_{t}} & \tilde{U} U_{t} & \tilde{U O} \\
\tilde{O E_{t}} & \tilde{O U} U_{t} & \tilde{O O}{ }_{t}
\end{array}\right]
$$

Remember that the reporting error matrix is

$$
B^{T}=\left[\begin{array}{lll}
b_{11} & b_{21} & b_{31} \\
b_{12} & b_{22} & b_{32} \\
b_{13} & b_{23} & b_{33}
\end{array}\right]
$$

where $b_{i j}=\operatorname{Pr}(Y=j \mid \tilde{Y}=i)$ is the probability that a worker whose true labor force status is in $i$ reports being in labor force status $j$. Then, $N_{k l}$, the reported number of workers transitioning from labor force status $k$ to $l$ for $k, l \in\{E, U, O\}$ is expressed in terms of reporting error probability $b$ and true labor force flows $\tilde{N}$ as

$$
N_{k l}=\sum_{i=1}^{3} \sum_{j=1}^{3} b_{i k} b_{j l} \tilde{N}_{i j} \text { for } k, l \in\{E, U, O\}
$$

where $\tilde{N}_{i j}$ is the $(i, j)$ th element of matrix $\tilde{N}$ : the true labor force flows of workers transitioning from labor force status $i$ to $j$. The intuition of equation (10) is as follows. The true flow of workers transitioning from labor force status $i$ to $j$ for $i, j \in\{E, U, O\}$ is recorded as a flow of workers transitioning from $k$ to $l$ with probability $b_{i k} b_{j l}$. Therefore, the total reported number of workers transitioning from $k$ to $l$ can be obtained by the weighted sum of the true number of workers transitioning from $i$ to $j$ for all possible transitions $i, j \in\{E, U, O\}$, with weights given 
by $b_{i k} b_{j l}$.

The reported labor force flows $N$ can then be expressed in a matrix form as a function of the true labor force flows $\tilde{N}$ and a reporting error matrix $B$ as follows.

$$
N_{t}=B^{T} \tilde{N}_{t} B
$$

If $B$ is invertible, then the true labor force flows can be calculated from equation (11) as

$$
\tilde{N}_{t}=\left(B^{T}\right)^{-1} N_{t}(B)^{-1}
$$

Note that there is nothing that prevents $\tilde{N}$ from being negative. In Poterba and Summers (1986), the classification error matrix for the male population show implied transition probabilities that are negative. As shown later, this is the case for FH estimates and occasionally true for PS estimates once applied to the data between 1996 to 2018. The true labor force flows from equation (12) can then be used to calculate the transition probabilities as

$$
\tilde{P}_{i j, t}=\frac{\tilde{i j_{t}}}{\sum_{j=1}^{3} \tilde{i j_{t}}}
$$

for $i, j \in\{E, U, O\}$

\subsection{Adjusted Transition Probabilities}

Using the adjustment procedures described above, Figure 2 plots the time series of unadjusted and adjusted transition probabilities based on the reporting error probabilities by AZ, PS, FH, and the estimates of this paper-HMM. Table 4 (2) shows corresponding historical average of transition probabilities between 1996 and 2018. We find that the reporting errors by Feng and $\mathrm{Hu}$ (2013) imply negative transition probabilities for some series. For my HMM estimates, as I imposed the first order Markov assumption and jointly estimated time varying true labor force transition probabilities $A$, we can ensure that the transition probabilities stay positive and do not exceed 100 percent. My approach also has an advantage in that I do not have to calculate 
Figure 2: Adjusted Transition Probabilities
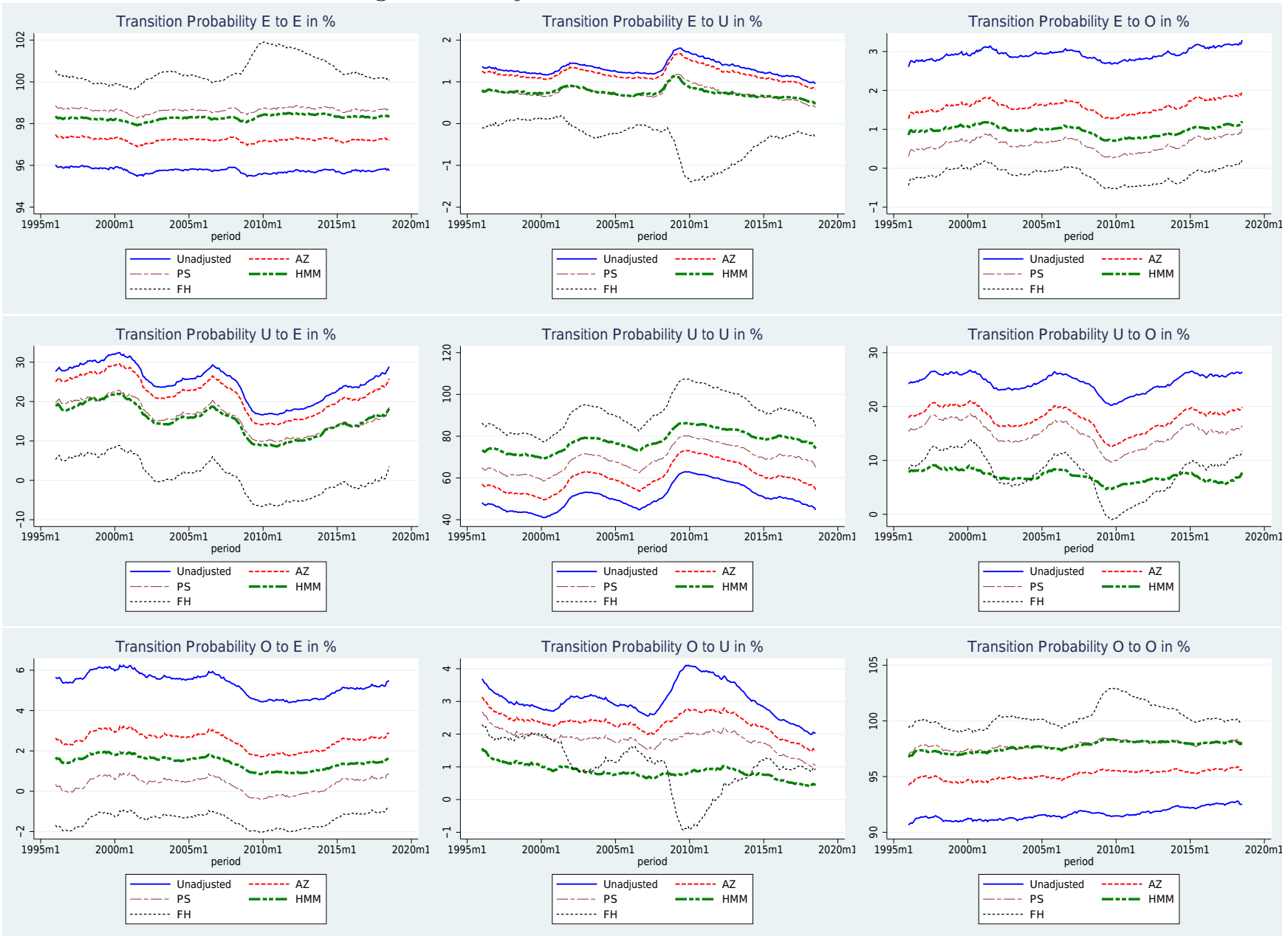
the implied transition probabilities for the true labor force status using equations (12) and (13).

I compare the HMM estimates against other estimates. First, the probabilities of staying in the same labor force status, (i.e., $\operatorname{Pr}\left(\tilde{Y}_{t+1}=i \mid \tilde{Y}_{t}=i\right)$ for $\left.i=1,2,3\right)$ are all higher than corresponding unadjusted and AZ probabilities, smaller than FH estimates, and very similar to PS estimates. The probability of transitioning from employment to unemployment is 0.7 percent on average and also smaller than unadjusted, and AZ. The probability of transitioning from unemployment to employment (roughly job finding probability) is around 15 percent on average and is also smaller than unadjusted (25 percent) and AZ (22 percent), but very similar to PS estimates (16 percent). Thus, the HMM adjustment of transition probabilities revise the unadjusted transition probabilities in the same direction (AZ, PS, and FH), and the degree of its adjustment is in general greater than AZ and PS, but smaller than FH.

\section{Contribution to Unemployment Fluctuations}

How much does the adjustment in transition probabilities matter for labor market dynamics? To answer this question, I examine the contributions of fluctuations in the transition probabilities to the fluctuations in the unemployment rate and the employment population ratios. The previous literature showed two key results. First, Shimer (2012) showed that the fluctuations in the unemployment rate are mostly explained by fluctuations in job finding rates or transitions out of unemployment ("Outs") rather than by fluctuations in job separation rates or transition into unemployment ("ins"). That is, "outs" win. Second, Elsby, Hobijn, and Sahin (2015) showed that the participation margin explains a large fraction, around one-third, of unemployment fluctuations. However, the results in this paper suggest that the misclassificaiton adjustment would still support the theory that "outs" win but moderate it. Misclassification correction also moderates the importance of participation margin in explaining unemployment fluctuations.

I follow Shimer (2012) to estimate the contribution of each transition probability to explaining the unemployment fluctuations, and compare their magnitudes under (1) no adjustment, (2) 
Abowd and Zellner (AZ) adjustment, and (3) HMM adjustment. As shown in the previous section, transition probabilities implied by Feng and Hu (2013) and Poterba and Summer (1986) have transition probabilities in some periods below 0 or above 100 and thus cannot be compared in this analysis.

In a continuous time framework, the labor market dynamics are governed by the following system of equations.

$$
\left[\begin{array}{c}
\dot{E} \\
\dot{U} \\
\dot{O}
\end{array}\right]=\left[\begin{array}{ccc}
\lambda_{E E} & \lambda_{U E} & \lambda_{O E} \\
\lambda_{E U} & \lambda_{U U} & \lambda_{O U} \\
\lambda_{E O} & \lambda_{U O} & \lambda_{O O}
\end{array}\right]\left[\begin{array}{c}
E \\
U \\
O
\end{array}\right]
$$

with $E+U+O=1$ (normalization) and $\lambda_{i i}=-\sum_{j \neq i} \lambda_{i j}$ where $\lambda_{i j}$ is the rate of transition from labor force status $i$ to $j$ in $i, j \in\{E, U, O\}$.

The system of equations in (14) can be reduced to system of employment and unemployment:

$$
\underbrace{\left[\begin{array}{c}
\dot{E} \\
\dot{U}
\end{array}\right]}_{\equiv \dot{s}_{t}}=\underbrace{\left[\begin{array}{cc}
-\lambda_{E U}-\lambda_{E O}-\lambda_{O E} & \lambda_{U E}-\lambda_{O E} \\
\lambda_{E U}-\lambda_{O U} & -\lambda_{U E}-\lambda_{U O}-\lambda_{O U}
\end{array}\right]}_{\equiv \tilde{F}_{t}} \underbrace{\left[\begin{array}{c}
E \\
U
\end{array}\right]}_{\equiv s_{t}}+\underbrace{\left[\begin{array}{c}
\lambda_{O E} \\
\lambda_{O U}
\end{array}\right]}_{\equiv w_{t}}
$$

In steady state, $\dot{s}_{t}=\mathbf{0}$, we have

$$
\bar{s}=\tilde{F}^{-1} w
$$

Therefore, the steady state employment population share $e_{s s}=\frac{E_{s s}}{E_{s s}+U_{s s}+O_{s s}}=E_{s s}$ and the unemployment rate $u_{s s}=\frac{U_{s s}}{E_{s s}+U_{s s}}$ can be expressed as a function of transition rates $\lambda_{i j}$ for $i \neq j$. The implied steady state unemployment rate (employment-population ratio) from equation (16) is fairly close to the observed series in the data. Exploiting this relationship, I can calculate the contribution of one particular transition rate $\lambda_{i j}$ to the overall fluctuations in the unemployment rate (employment population ratio) by allowing it to follow its time series value while fixing the rest of the transition rates $\lambda_{i j}$ at their historical average. The results of this analysis are summarized in Table 5.

Each component in Table 5 shows the contributions of fluctuations in transition rate $\lambda_{i j}$ 
Table 5: Contributions of Transitions to the UR and EP Ratio 1996-2018 Unemployment Rate

\begin{tabular}{|c|c|c|c|c|c|c|c|c|c|c|c|c|}
\hline & \multirow{2}{*}{\multicolumn{3}{|c|}{ 1996-2007 }} & \multirow{2}{*}{\multicolumn{3}{|c|}{$1996-2018$}} & \multirow{2}{*}{\multicolumn{3}{|c|}{$1996-2007$}} & \multirow{2}{*}{\multicolumn{3}{|c|}{$1996-2018$}} \\
\hline & & & & & & & & & & & & \\
\hline & $R$ & $A Z$ & $H M M$ & $R$ & $A Z$ & $H M M$ & $R$ & $A Z$ & $H M M$ & $R$ & $A Z$ & $H M M$ \\
\hline$\lambda_{E U}$ & 0.20 & 0.24 & 0.30 & 0.20 & 0.25 & 0.27 & 0.14 & 0.11 & 0.16 & 0.22 & 0.18 & 0.12 \\
\hline$\lambda_{E O}$ & -0.07 & -0.11 & -0.08 & -0.05 & -0.09 & -0.09 & -0.46 & -0.47 & 0.11 & -0.30 & -0.36 & -0.05 \\
\hline$\lambda_{U E}$ & 0.53 & 0.57 & 0.53 & 0.46 & 0.50 & 0.52 & 0.49 & 0.39 & 0.21 & 0.59 & 0.5 & 0.23 \\
\hline$\lambda_{U O}$ & 0.14 & 0.12 & 0.09 & 0.12 & 0.11 & 0.07 & -0.14 & -0.15 & -0.07 & -0.17 & -0.2 & -0.04 \\
\hline$\lambda_{O E}$ & 0.10 & 0.16 & 0.14 & 0.09 & 0.13 & 0.13 & 0.87 & 0.89 & 0.42 & 0.65 & 0.68 & 0.45 \\
\hline$\lambda_{O U}$ & 0.10 & 0.01 & 0.00 & 0.15 & 0.06 & 0.04 & 0.13 & 0.28 & 0.23 & -0.05 & 0.14 & 0.19 \\
\hline$\lambda_{U E}+\lambda_{E U}$ & 0.73 & 0.81 & 0.83 & 0.66 & 0.75 & 0.79 & 0.63 & 0.50 & 0.37 & 0.81 & 0.68 & 0.35 \\
\hline$\lambda_{O U}+\lambda_{U O}$ & 0.24 & 0.13 & 0.09 & 0.27 & 0.17 & 0.11 & & & & & & \\
\hline$\lambda_{E O}+\lambda_{O E}$ & & & & & & & 0.41 & 0.42 & 0.53 & 0.35 & 0.32 & 0.40 \\
\hline
\end{tabular}

$R$ is reported series without any misclassification adjustment, $A Z$ is Abowd and Zellner's (1985), and HMM is HMM-adjusted series.

to unemployment rates and employment population ratio. One main conclusion from Shimer (2012) is that the fluctuations in job finding rate $\lambda_{U E}$ explains fluctuation in the unemployment rate more than job separation rate $\lambda_{E U}\left(\lambda_{U E}>\lambda_{E U}\right)$ or "Out Wins". This implies that the unemployment rate fluctuates over the business cycle not because workers lose job but because workers have a hard time finding a job. Both HMM-adjusted transition rates and Abowd-Zellner adjusted transition rates still support the conclusion that "Out Wins" but moderate it. For 19962007, HMM adjustment claims that "Outs" $\left(\lambda_{U E}^{H M M}=0.53\right)$ still win over "Ins" $\left(\lambda_{E U}^{H M M}=0.30\right)$. However, the role of "Ins" $\left(\lambda_{E U}^{H M M}=0.30\right)$ is higher than previously suggested $\left(\lambda_{E U}^{R}=0.2\right)$. The fraction of "In" $\frac{\lambda_{E U}}{\lambda_{U E}+\lambda_{E U}}$ goes up from around $100 \times \frac{0.2}{0.53+0.2} \approx 27.4$ percent without adjustment to $100 \times \frac{0.3}{0.53+0.3} \approx 36.1$ percent with the HMM adjustment. The qualitative results are robust to different time periods.

The fraction of the employment-population ratio fluctuation explained by the unemploymentto-employment transition, $\lambda_{U E}$, declines from 0.49 and 0.39 in unadjusted and AZ-adjusted series to merely 0.21 in the HMM adjusted series for 1996-2007. The fraction explained by the fluctuations in the employment-to-unemployment transition, $\lambda_{E U}$, goes up from 0.14 under no adjustment to 0.16 under the HMM adjustment, fairly close to the contribution by $\lambda_{U E}$.

Elsby, Hobijn, and Sahin (2015) study the importance of labor force participation margin in explaining the fluctuations in the unemployment rate following a similar method as in Shimer 
(2012). They estimate that approximately 26-36 percent of the unemployment dynamics are attributed to the flow probabilities between unemployment and nonparticipation $\left(\lambda_{U O}+\lambda_{O U}\right)$. Based on my analysis, this conclusion still holds for unadjusted series (around 25 percent). Yet, HMM-adjusted transition rates suggest that the participation margin can only explain approximately 10 percent of unemployment fluctuations. Thus, the importance of participation margin could be much smaller than previously argued.

Why does the HMM suggest less significant role of participation margin? The HMM adjustment mutes the importance of the participation margin in accounting for the unemployment fluctuations by making the movement in and out of nonparticipation (O) much less cyclical. The HMM particularly mutes the cyclicality of the nonparticipant-to-unemployment (O-U) and unemployment-to-non-partcipation (U-O) transitions (Figure 2). Under the HMM adjustment, truly unemployed workers have a high probability of incorrectly reporting to be nonparticipant (i.e $\left.\operatorname{Pr}\left(Y_{t}=O \mid \tilde{Y}_{t}=U\right)=16.1\right)$. With the error-correction, nonparticipants who tend to move between unemployment and nonparticipants over business cycle are mostly corrected to be unemployed.

Whether Ins or Outs win is important for policymakers. If a significant fraction of unemployment fluctuations is explained by job separation (Ins), policymakers could reduce unemployment fluctuations by focusing more on measures to discourage firms from firing workers through tax incentives or encourage firms to adjust labor via an intensive margin (number of hours worked) rather than an extensive margin (number of employees). On the other hand, if unemployment fluctuations are mostly explained by difficulties in finding jobs, policymakers could put more emphasis on active labor market policies such as training programs, job-search assistance, and direct job creation. This paper suggests that Outs win but Ins also do matter, calling for policymakers not to discard the job separation margin. 


\section{Conclusion}

This paper revisited the issue of classification errors in the U.S. Current Population Survey. While the results still support the previous literature's conclusion that the job finding probability

plays a more important role in explaining unemployment fluctuations ("outs of unemployment") than the job separation probability does ("ins to unemployment"), they moderate the conclusion that "Out Wins". Moreover, once the proposed adjustment is applied, the importance of the participation margin in explaining unemployment fluctuations becomes smaller than previously argued - around 10 percent in this paper vs previous estimates of 20 to 30 percent (Elsby, Hobijn and Sahin, 2015). Therefore, the misclassification correction procedures in the labor force survey continue to be an important issue in understanding labor market dynamics. The results of this paper suggest that policymakers should pay closer attention to the job separation margin than previously thought and less on the participation margin. 


\section{References}

[1] Abowd, J. M., and Zellner, A. (1985), "Estimating Gross Labor-Force Flows," Journal of Business \& Economic Statistics, 3.3, 254-283.

[2] Allman, E. S., Matias, C., and Rhodes, J. A. (2009), "Identifiability of Parameters in Latent Structure Models with Many Observed Variables," Annals of Statistics, 37.6A, 3099-3132.

[3] Biemer, P. P., and Bushery, J. M. (2000), "On the Validity of Markov Latent Class Analysis for Estimating Classification Error in Labor Force Data," Survey Methodology, 26.2, 139-152.

[4] Blanchard, O. J., and Diamond, P. (1990), "The Cyclical Behavior of the Gross Flows of U.S. Workers," Brookings Papers on Economic Activity, vol. 1990, no. 2, 1990, 85-155.

[5] Elsby, M. W. L., Hobijn, B., and Sahin, A. (2015), "On the Importance of the Participation Margin for Labor Market Fluctuations," Journal of Monetary Economics, 72, 64-82.

[6] Feng, S., and Hu, Y. (2013), "Misclassification Errors and the Underestimation of the US Unemployment Rate," American Economic Review, 103.2, 1054-1070.

[7] Hu, Y. (2008), "Identification and Estimation of Nonlinear Models with Misclassification Error using Instrumental Variables: a General Solution," Journal of Econometrics, 144, $27-61$.

[8] Hu, Y. (2017) "The Econometrics of Unobservables: Applications of measurement error models in empirical industrial organization and labor economics", Journal of Econometrics, $200,2,154-168$.

[9] Madrian, B. C., and Lefgren, L. J. (1999), "A Note on Longitudinally Matching Current Population Survey (cps) Respondents," NBER Technical Working Papers, 247.

[10] Meyer, B. D. (1988), "Classification-Error Models and Labor-Market Dynamics," Journal of Business 8 Economic Statistics, 6.3, 385-390. 
[11] Mortensen, D. T., and Pissarides, C. A. (1994), "Job Creation and Job Destruction in the Theory of Unemployment," Review of Economic Studies, 61(3), 397-415.

[12] Poterba, J. M., and Summers, L. H. (1986), "Reporting Errors and Labor Market Dynamics," Econometrica, 54.6, 1319-1338.

[13] Poterba, J. M., and Summers, L. H. (1995), "Unemployment Benefits and Labor Market Transitions: A Multinomial Logit Model with Errors in Classification," Review of Economics and Statistics, 77, 207-216.

[14] Singh, A., and Rao, J. (1995), "On the Adjustment of Gross Flow Estimates for Classification Error With Application to Data from the Canadian Labour Force Survey," Journal of the American Statistical Association, 90(430), 478-488.

[15] Shimer, R. (2005). "The Cyclical Behavior of Equilibrium Unemployment and Vacancies." American Economic Review, 95.1, 25-49.

[16] Shimer, R. (2008), "The Probability of Finding a Job," American Economic Review, 98(2), 268-273.

[17] Shimer, R. (2012), "Reassessing the Ins and Outs of Unemployment," Review of Economic Dynamics, 15.2, 127-148. 


\section{Appendix}

This appendix accompanies the paper "Are Labor Market Indicators Telling the Truth? Role of Measurement Error in the US Current Population Survey" previously circulated as "Reassessing Classification Errors in the Analysis of Labor Market Dynamics". Section 1 provides the details of the maximum likelihood estimation used in the paper and compare the estimation results to those based on the eigenvalue-eigenvector decomposition method. Section 2 compares the identification results of Allman, Matias and Rhodes (2009) against Feng and Hu (2013). Section 3 tests the validity of the first order Markov assumption for the true labor force status. It presents estimation results using the simulated data when a data generating process (DGP) is a second order Markov process.

\section{Appendix 1: Maximum Likelihood Estimation}

Appendix 1 shows the maximum likelihood estimation of this latent variable model. Given that each worker in the data experiences three labor force status $(E, U, O)$ during the three consecutive months, we have $3^{\bar{T}}=3^{3}=27$ possible paths a worker could take. For instance, one possible employment history is $l=1$ : a worker is employed for the entire three months $Y_{0}=1, Y_{1}=1, Y_{2}=1$. Let $f_{l}$ be the total number of workers in $l$ th possible path, $l_{t}$ be individual l's labor force status in month $t$. Given the model parameters $\Lambda=(A, B, \pi)$, the likelihood of jointly observing all 27 possible paths, $\operatorname{Pr}\left(Y_{0}=l_{0}, Y_{1}=l_{1}, Y_{2}=l_{2}\right)$ for $i, j, k \in\{E, U, O\}$ for all the workers $l \in \mathcal{L}$ in the data can be expressed as follows:

$$
L\left(\Lambda \mid Y_{0}, Y_{1}, Y_{2}\right)=\prod_{l=1}^{27}\left(\operatorname{Pr}\left(Y_{0}=l_{0}, Y_{1}=l_{1}, Y_{2}=l_{2}\right)\right)^{f_{l}}
$$

where $\operatorname{Pr}\left(Y_{0}=l_{0}, Y_{1}=l_{1}, Y_{2}=l_{2}\right)$ can be expressed as:

$$
\sum_{\tilde{Y}_{0}=1}^{3}\left\{\operatorname{Pr}\left(\tilde{Y}_{0}\right) \operatorname{Pr}\left(Y_{0}=l_{0} \mid \tilde{Y}_{0}\right) \sum_{\tilde{Y}_{1}=1}^{3}\left[\operatorname{Pr}\left(\tilde{Y}_{1} \mid \tilde{Y}_{0}\right) \operatorname{Pr}\left(Y_{1}=l_{1} \mid \tilde{Y}_{1}\right) \sum_{\tilde{Y}_{2}=1}^{3} \operatorname{Pr}\left(\tilde{Y}_{2} \mid \tilde{Y}_{1}\right) \operatorname{Pr}\left(Y_{2}=l_{2} \mid \tilde{Y}_{2}\right)\right]\right\}
$$




$$
=\sum_{\tilde{Y}_{0}=1}^{3}\left\{\pi_{\tilde{Y}_{0}} b_{\tilde{Y}_{0} Y_{0}}\left(l_{0}\right) \sum_{\tilde{Y}_{1}=1}^{3}\left[a_{\tilde{Y}_{0} \tilde{Y}_{1}=l_{1}} b_{\tilde{Y}_{1} Y_{1}}\left(l_{1}\right) \sum_{\tilde{Y}_{2}=1}^{3} a_{\tilde{Y}_{1} \tilde{Y}_{2}} b_{\tilde{Y}_{2} Y_{2}}\left(l_{2}\right)\right]\right\}
$$

In a matrix form, equation (18) can be expressed as

$$
\operatorname{Pr}\left(Y_{0}=l_{0}, Y_{1}=l_{1}, Y_{2}=l_{2}\right)=\left(\pi \operatorname{diag}\left(\beta_{\cdot l_{0}}\right)\left(\prod_{t=1}^{2} A^{*} \operatorname{diag}\left(\beta_{\cdot l_{t}}\right)\right) 1^{\prime}\right)
$$

Therefore, the log likelihood function can be expressed as

$$
\log L\left(\Lambda \mid Y_{0}, Y_{1}, Y_{2}\right)=\sum_{l=1}^{27} f_{l} \times \ln \left(\operatorname{Pr}\left(Y_{0}=l_{0}, Y_{1}=l_{1}, Y_{2}=l_{2}\right)\right)
$$

We can then apply the Expectation and Maximization (EM) algorithm to find the parameters that maximize the $\log$-likelihood function in equation (20). When we allow $A$ to vary over time, $A_{\tau}$ for $t=1996 m 1$ to $2018 m 9$, while fixing the error reporting matrix $B=\left(\beta_{\cdot 1}^{T}, \beta_{\cdot 2}^{T}, \beta_{\cdot 3}^{T}\right)$, the log-likelihood in equation (20) becomes

$$
\log L\left(\Lambda \mid Y_{0, \tau}, Y_{1, \tau}, Y_{2, \tau}\right)=\sum_{\left\{l\left\{l_{0}, l_{2}, l_{2}\right\}=1\right.}^{27} f_{l, t} \times \ln \left[\pi \operatorname{diag}\left(\beta_{l_{0}}\right)\left(\prod_{t=1}^{2} A_{\tau}^{*} \operatorname{diag}\left(\beta_{l_{2}}\right)\right)\right] 1^{\prime}
$$

for $\tau=1, \ldots, \bar{T}$. Therefore, the information of the number of workers in each possible employment path $l \in M^{3}$ allows us to estimate the model parameters using the maximum likelihood via the EM algorithm.

Table 6 shows the estimation results based on Feng and Hu (2013) estimation strategy (Column 1) and those based on a maximum likelihood estimation (MLE) in the previous section of Appendix Column (2). Note that the Feng and Hu (2012) estimation strategy was employed to the data from the three consecutive months unlike in the original paper (Feng and $\mathrm{Hu}, 2013$ ). Depending on the choices of the observation in $t+1, Y_{t+1}$, the FH's estimation slightly changes. The Maximum Likelihood Estimation (MLE) provides estimates of measurement error matrix that are consistent with those based on the eigenvalue-eigenvector decomposition proposed by Feng and $\mathrm{Hu}$ (2013), which is approximately the average of the measurement error matrix based on the FH estimation strategy. 
Table 6: Comparison of FH and HMM estimation

\begin{tabular}{l|ccc|ccc} 
& \multicolumn{3}{c}{$(1) B_{\text {Decomp }}$} & \multicolumn{3}{c}{$(2) B_{M L E}$} \\
& $Y_{t+1}=1$ & $Y_{t+1}=2$ & $Y_{t+1}=3$ & $H M M$ & $95 \%$ CI & $S E$ \\
\hline $\operatorname{Pr}(E \mid \tilde{E})$ & 98.65 & 99.62 & 98.8 & 98.69 & {$[98.57,98.81]$} & 0.06 \\
$\operatorname{Pr}(U \mid \tilde{E})$ & 0.44 & 0.38 & 0.26 & 0.42 & {$[0.34,0.5]$} & 0.04 \\
$\operatorname{Pr}(O \mid \tilde{E})$ & 0.91 & 0 & 0.94 & 0.89 & {$[0.81,0.98]$} & 0.04 \\
$\operatorname{Pr}(E \mid \tilde{U})$ & 6.71 & 5.97 & 11.28 & 7.03 & {$[5.77,8.3]$} & 0.65 \\
$\operatorname{Pr}(U \mid \tilde{U})$ & 74.52 & 80.21 & 74.68 & 77.8 & {$[75.88,79.72]$} & 0.98 \\
$\operatorname{Pr}(O \mid \tilde{U})$ & 18.77 & 13.82 & 14.04 & 15.16 & {$[13.52,16.81]$} & 0.84 \\
$\operatorname{Pr}(E \mid \tilde{O})$ & 1.35 & 7.93 & 1.36 & 1.43 & {$[1.25,1.61]$} & 0.09 \\
$\operatorname{Pr}(U \mid \tilde{O})$ & 0.17 & 1.19 & 1.04 & 1.04 & {$[0.85,1.22]$} & 0.1 \\
$\operatorname{Pr}(O \mid \tilde{O})$ & 98.49 & 90.88 & 97.61 & 97.53 & {$[97.27,97.8]$} & 0.13 \\
\hline$B_{D e c o m p}$ and $B_{M L E}:$ misclassification matrix estimated using the eigenvalue- \\
eigenvector method and the maximum likelihood (MLE), respectively. \\
$Y_{t+1}=i$ : observations with labor force status $i \in\{1,2,3\}$ in $t+1$ was used \\
in the eigenvalue-eigenvector decomposition approach to calculate the \\
measurement error matrix.
\end{tabular}

\section{Appendix 2: $\mathrm{Hu}$ (2008) and Allman, Mathias, and Rhodes}

\section{(2009)}

This appendix compares the identification results from $\mathrm{Hu}$ (2008) and Feng and $\mathrm{Hu}(2013)$ in the main text and those of Allman et al (2009) for a hidden Markov model, the measurement error model in this paper. There are several differences between the identification results in Allman et al (2009) and those in $\mathrm{Hu}$ (2008) and Feng and $\mathrm{Hu}$ (2013). Allman et al (2009) provide a local identification result while Feng and $\mathrm{Hu}$ (2013) and $\mathrm{Hu}$ (2008) provide a global identification. While Allman et al (2009) considers a general case, $\mathrm{Hu}$ (2008) provide more primitive and economically meaningful conditions. For instance, Kruskal rank is the maximum value of $k$ such that any $k$ columns of a matrix are linearly independent, then $k$ is the Kruskal rank of the matrix. On the other hand, Feng and $\mathrm{Hu}$ (2013) provides much more economically meaningful and easily testable identification assumptions a regular rank condition on the observables: $k$ columns of a matrix are linearly independent. While the Feng and $\mathrm{Hu}$ (2013) uses a subset of the dataset for $Y_{t+1}=1$, the estimation method used in this paper utilizes all possible observations in $Y_{t+1}=i$ for $i \in\{1,2,3\}$ for $\Psi_{1, Y_{t}, Y_{t-1}}$ to estimate the parameters of the model. 
I present this local identification results from Allman et al (2009) to show how model parameters, $\pi, \mathrm{B}$, and $A$, can be recovered from the three months of employment panel data. Before I do so, notice that relabeling or "label swapping" the states, such as assigning 1 to U and 2 to $E$ instead of the other way around, would not change the distribution of the observations. Thus, we show that the identifications are unique up to label swapping. Allman, Mathias, and Rhodes (2009) applies algebraic results from Kruskal (1976) to prove the uniqueness of parameter estimates given an 3 way array up to label swapping.

Assumption 1 (Conditional Independence of $B$ ) and Assumption 2 (First order Markov assumption of $A$ ) in the main text remain the same. However, instead of using Assumption 3 and 4 on restrictions on observable distributions, I assume the following: (1) the matrix of measurement error matrix $B, \operatorname{Pr}\left(\tilde{Y}_{t}=k \mid Y_{t}=i\right)$ has a full rank; and (2) a first-order Markov transition matrix for true labor force status, A, is invertible. Assumption 5 (Ordering) in the main text remains the same: his or her true labor force status than any other $\operatorname{Pr}\left(Y_{t}=i \mid \tilde{Y}_{t}=i\right)>\operatorname{Pr}\left(Y_{t}=k \mid \tilde{Y}_{t}=i\right)$ for $k \neq i$ for $i \in\{1,2,3\}$. This allows a researcher to pin down the true labor force status. While it is not possible to check the full rank conditions of the true measurement error matrix $B$ and true first order transition matrix for the true labor force status $A$, estimated $B$ and $A$ are both invertible.

Following equation (18), we can rewrite the joint PDF of $\left(Y_{1}, Y_{2}, Y_{3}\right)$ as follows:

$$
\begin{gathered}
\operatorname{Pr}\left(Y_{0}=l_{0}, Y_{1}=l_{1}, Y_{2}=l_{2}\right) \\
=\sum_{\tilde{Y}_{0}=1}^{3}\left\{\pi_{\tilde{Y}_{0}} b_{\tilde{Y}_{0} Y_{0}}\left(l_{0}\right) \sum_{\tilde{Y}_{1}=1}^{3}\left[a_{\tilde{Y}_{0} \tilde{Y}_{1}=l_{1}} b_{\tilde{Y}_{1} Y_{1}}\left(l_{1}\right) \sum_{\tilde{Y}_{2}=1}^{3} a_{\tilde{Y}_{1} \tilde{Y}_{2}} b_{\tilde{Y}_{2} Y_{2}}\left(l_{2}\right)\right]\right\} \\
=\sum_{\tilde{Y}_{1}=1}^{3}\left\{\left[\sum_{\tilde{Y}_{0}=1}^{3} \pi_{\tilde{Y}_{0}} b_{\tilde{Y}_{0} Y_{0}}\left(l_{0}\right) a_{\tilde{Y}_{0} \tilde{Y}_{1}=l_{1}}\right] b_{\tilde{Y}_{1} Y_{1}}\left(l_{1}\right)\left[\sum_{\tilde{Y}_{2}=1}^{3} a_{\tilde{Y}_{1} \tilde{Y}_{2}} b_{\tilde{Y}_{2} Y_{2}}\left(l_{2}\right)\right]\right\}
\end{gathered}
$$

Let $B^{T}=\left[\beta_{\cdot 1}, \beta_{\cdot 2}, \beta_{\cdot 3}\right]^{T}$ be the $3 \times 3$ transpose of reporting error matrix $B$, where $\beta_{\cdot i}=$ $\left(b_{1 i}, b_{2 i}, b_{3 i}\right)^{T}$ is a vector with probability of reporting $i$ given a different true employment status. Define $\Pi \equiv \operatorname{diag}\left(\pi_{1}, \pi_{2}, \pi_{3}\right)$. Then we can rewrite equation as

$$
L=\sum_{\tilde{Y}_{1}=1}^{3}\left(B^{T} \Pi A\right)_{\tilde{Y}_{1}} \otimes \beta_{\tilde{Y}_{1}} \otimes\left(B^{T} A^{T}\right)_{\tilde{Y}_{1}}
$$


where $(Q)_{\tilde{Y}_{1}}$ is the $\tilde{Y}_{1}$ th column of matrix $Q$. Define

$$
\begin{gathered}
Q_{1}=B^{T} \Pi A \\
Q_{2}=B^{T} \\
Q_{3}=B^{T} A^{T}
\end{gathered}
$$

Then, (22) can be expressed as

$$
L=\sum_{\tilde{Y}_{1}=1}^{3}\left(Q_{1}\right)_{\tilde{Y}_{1}} \otimes\left(Q_{2}\right)_{\tilde{Y}_{1}} \otimes\left(Q_{3}\right)_{\tilde{Y}_{1}}
$$

Now we state Kruskal's theorem.

\section{Kruskal's Theorem}

Let $Q_{i}=\left[q_{i 1}, \ldots, q_{i n}\right] \in R^{m_{t} \times n}$ for some $m_{t}, n \in \mathbb{Z}^{+}$for $t=1,2,3$ and $i=1,2,3$. Define the three way $m_{1} \times m_{2} \times m_{3}$ arrays

$$
\bar{P}=\sum_{j=1}^{n}\left(Q_{1}\right)_{j} \otimes\left(Q_{2}\right)_{j} \otimes\left(Q_{3}\right)_{j}
$$

Let $r_{i}=\max \left\{k:\right.$ all collections of $k$ columns of $Q_{i}$ are linearly independent $\}$ (called Kruskalrank). Then, if $r_{1}+r_{2}+r_{3} \geq 2 n+2$ then $\bar{P}$ uniquely determins matrics $Q_{i}$ up to a label swapping. Note that if $Q \in R^{M \times r}$ has rank $r$, it also has Kruskal-rank $r$.

Therefore, if matrices $Q_{1}=B^{T} \Pi A, Q_{2}=B^{T}$ and $Q_{3}=B^{T} A^{T}$ in equation (26) all have full rank $r=3$, then it satisfies the Kruskal's condition $r_{1}+r_{2}+r_{3} \geq 2 n+2 \Longleftrightarrow 3+3+3 \geq 2 * 3+2$. Therefore, we can uniquely identify $Q_{1}, Q_{2}$, and $Q_{3}$ up to label swapping. Given that $Q_{1}, Q_{2}$, and $Q_{3}$ are $3 \times 3$ square matrices, if ranks of $Q_{1}, Q_{2}$, and $Q_{3}$ are 3 , then it would also imply that Kruskal rank would be 3 . Indeed, the estimated $Q_{1}=B^{T} \operatorname{diag}(\Pi) A, Q_{2}=B^{T}$, and $Q_{3}=B^{T} A^{T}$ have full rank given that $A$ and $B$ have full rank, and their Kruskal rank are also 3. 
Once we uniquely identify $Q_{1}, Q_{2}$, and $Q_{3}$, then we can recover $A, B, \Pi$ from equations (23), (24) and (25). Equation (24) provides $B^{T}, A$ can then be recovered from equation (25) (i.e. $\left.A^{T}=\left(B^{T}\right)^{-1} Q_{3}\right)$ and from equation $(23), \Pi=\left(B^{T}\right)^{-1} Q_{1} A^{-1}$.

\section{Appendix 3: Validity of First Order Markov Assumptions}

This Appendix tests the validity of the first order Markov (FOM) assumption in the paper. The goal of this paper is to propose a misclassification correction model to accurately measure the workers' flow between employment, unemployment, and nonparticipation over month $t$ and $t+1$ in the Current Population Survey. As a sensitivity analysis, several reviewers asked to provide results when the data generating process (DGP) is relaxed. I assume that a data generating process (DGP) is a second-order Markov process and simulate the data for three months, and estimate a hidden Markov model with a first-order Markov assumption using this simulated data. I show that the results are generally robust to the DGP being not a first order Markov process.

Once I estimate a hidden Markov model, I first compare the error probability matrix, $B$, can be recovered. The distribution of true labor force history, $\operatorname{Pr}\left(\tilde{Y}_{t+1}=k, \tilde{Y}_{t}=j, \tilde{Y}_{t-1}=i\right)$ for $i, j, k \in\{E, U, O\}$ can be precisely estimated. The weighted mean absolute errors between the true underlying distribution of true labor force history, $\operatorname{Pr}\left(\tilde{Y}_{t+1}=k, \tilde{Y}_{t}=j, \tilde{Y}_{t-1}=i\right)_{D G P}$ , and the estimated distribution of true labor force history, $\operatorname{Pr}\left(\tilde{Y}_{t+1}=k, \tilde{Y}_{t}=j, \tilde{Y}_{t-1}=i\right)_{H M M}$ is merely 0.0014 percentage points. Particularly, the implied transition probability of true labor

market history, $\operatorname{Pr}\left(\tilde{Y}_{t+1} \mid \tilde{Y}_{t}\right)_{D G P}$, is not statistically different from the estimated $\operatorname{Pr}\left(\tilde{Y}_{t+1} \mid \tilde{Y}_{t}\right)_{H M M}$ for most cases. Therefore, for the purpose of the flow analysis, we could still use the first order Markov process assumption for the measurement error model.

\section{Simulation Exercise: DGP-a second order Markov process}

This subsection tests how far off an estimated hidden Markov model would be if the data generating process (DGP) was not first order Markov as in the assumption. As an example, I assume 
that the DGP follows a second order Markov process instead of a first order Markov process:

$$
\operatorname{Pr}\left(\tilde{Y}_{t} \mid \tilde{Y}_{t-1}, \tilde{Y}_{t-2}, \tilde{Y}_{\bar{t}}\right)=\operatorname{Pr}\left(\tilde{Y}_{t} \mid \tilde{Y}_{t-1}, \tilde{Y}_{t-2}\right) \text { for all } \bar{t} \neq \mathrm{t}, \mathrm{t}-1
$$

I define three objects.

\section{Initial w}

Let $\Xi$ be the initial distribution for the true labor force states (LFS) in $t-1, t-2$

$$
\Xi_{i j} \equiv \operatorname{Pr}\left(\tilde{Y}_{t-1}=j, \tilde{Y}_{t-2}=i\right) \text { for } i, j \in\{E, U, O\}
$$

\section{Second Order Markov Transition Matrix}

Let $\Psi$ be the second order transition matrix where $(i, j, k)$ element of this matrix is defined as:

$$
\psi_{i j k} \equiv \operatorname{Pr}\left(\tilde{Y}_{t}=k \mid \tilde{Y}_{t-1}=j, \tilde{Y}_{t-2}=i\right)
$$

\section{Measurement Error Matrix}

Let $B^{D G P}$ the true measurement error matrix where $(i, j)$ element of this matrix is defined as:

$$
b_{i j}^{D G P}=\operatorname{Pr}\left(Y_{t}=j \mid \tilde{Y}_{t}=i\right)
$$

Step 1: draw true labor force status (LFS) in period $t-1$ and $t-2\left(\tilde{Y}_{t-1}, \tilde{Y}_{t-2}\right)$ according to the initial distribution $\Xi_{i j}$.

Step 2: draw true LFS in period $t$ by using the second order Markov transition probability $\psi_{i j k}$ and true LFS in $t-1$ and $t-2,\left(\tilde{Y}_{t-1}=j, \tilde{Y}_{t-2}=i\right)$. For example, if the true LFS in $t-1$ and $t-2$ are $\left(\tilde{Y}_{t-1}=E, \tilde{Y}_{t-2}=E\right)$, then I use the first row of the matrix $\Psi$ (i.e. $\psi_{E E k}$ for $k \in\{E, U, O\})$ to draw the true LFS in period $t: \tilde{Y}_{t}=k$. 
Table 7: DGP: Second Order Markov Transition Matrix $\Psi$ : Second Order Markov Transition Matrix (DGP)

\begin{tabular}{cccc}
\multicolumn{4}{c}{$\operatorname{Pr}\left(Y_{t+1}=k \mid Y_{t-1}, Y_{t}\right)$} \\
\hline$Y_{t-1} Y_{t}$ & $Y_{t+1}=E$ & $Y_{t+1}=U$ & $Y_{t+1}=O$ \\
\hline$E E$ & 98.3 & 0.7 & 1.0 \\
$E U$ & 13.7 & 79.3 & 7.0 \\
$E O$ & 1.8 & 0.8 & 97.4 \\
$U E$ & 97.8 & 1.1 & 1.1 \\
$U U$ & 12.4 & 81.5 & 6.1 \\
$U O$ & 2.5 & 0.0 & 97.5 \\
$O E$ & 98.1 & 0.2 & 1.7 \\
$O U$ & 14.6 & 78.9 & 6.5 \\
$O O$ & 1.4 & 0.9 & 97.6 \\
\hline$Y_{t-1} Y_{t}$ means $\left(Y_{t-1}=i, Y_{t}=j\right)$ for $i, j \in\{E, U, O\}$. \\
For example, EU implies that $\left(Y_{t-1}=E, Y_{t}=U\right)$
\end{tabular}

Step 3: draw observed LFS in $t, t-1, t-2,\left(Y_{t}, Y_{t-1}, Y_{t-2}\right)$ using the measurement error matrix $\tilde{B}$ and the true LFS in $t, t-1, t-2:\left(\tilde{Y}_{t}, \tilde{Y}_{t-1}, \tilde{Y}_{t-2}\right)$.

Step 4: repeat step 1-3 for $N$ times to generate observed LFS with iid sampling.

I then estimate the HMM using the generated observed LFS with $N=60000$ observations and compare the estimated measurement error matrix, $B$, against the true measurement error matrix, $B^{D G P}$. I set a second order Markov transition matrix $\Psi$ and $B^{D G P}$ to be consistent with the data. Table 7 shows the second order Markov transition matrix used as a DGP. Table 8 shows the estimated results. It shows that the estimated measurement error matrix, $B$ (in column (2)), is close to the true data generating process (DGP), $B^{D G P}$. The true misclassification matrix, $B^{D G P}$, is within the $95 \%$ confidence interval of $B$, which was estimated using the simulated data.

To further check the validity of the first order Markov assumption in capturing the true labor force history, I also consider deviations in the $B^{D G P}$ itself. Define $B_{\max }^{D G P}$ and $B_{\min }^{D G P}$ as follows: I set off-diagonal elements of $B_{\max }^{D G P}$ to be +2 standard deviations of those in $B^{D G P}$ when standard errors were calculated using the estimates of the model based on the simulated data based on true data generating process. Similarly, I set $B_{\min }^{D G P}$ to be -2 standard deviations of those in 
Table 8: Estimation Results

\begin{tabular}{|c|c|c|c|c|c|c|c|}
\hline \multicolumn{4}{|c|}{$\begin{array}{c}\text { Misclassification Probabilities } \\
\operatorname{Pr}(j \mid \tilde{i})=\operatorname{Pr}\left(Y_{t}=j \mid \tilde{Y}_{t}=i\right) \text { for } i, j \in\{E, U, O\} \\
\text { (In percentage points) }\end{array}$} & \multicolumn{4}{|c|}{$\begin{array}{c}\text { Transition Probabilities } \\
\operatorname{Pr}(\tilde{j} \mid \tilde{i})=\operatorname{Pr}\left(\tilde{Y}_{t+1}=j \mid \tilde{Y}_{t}=i\right) \text { for } i, j \in\{E, U, O\} \\
(\text { In percentage points })\end{array}$} \\
\hline & $\begin{array}{c}(1) \\
B^{D G P} \\
\end{array}$ & $\begin{array}{c}(2) \\
B^{\text {Estimate }}\end{array}$ & $\begin{array}{c}(3) \\
95 \% \mathrm{CI} \\
\end{array}$ & & $\begin{array}{c}(1) \\
A^{\text {Implied }}\end{array}$ & $\begin{array}{l}(2) \\
A^{\text {est }}\end{array}$ & $\begin{array}{c}(3) \\
95 \% \mathrm{CI} \\
\end{array}$ \\
\hline $\operatorname{Pr}(E \mid \tilde{E})$ & 98.7 & 98.7 & {$[98.4,99.0]$} & $\operatorname{Pr}(\tilde{E} \mid \tilde{E})$ & 98.3 & 98.3 & {$[97.9,98.7]$} \\
\hline $\operatorname{Pr}(U \mid \tilde{E})$ & 0.4 & 0.5 & {$[0.3,0.6]$} & $\operatorname{Pr}(\tilde{U} \mid \tilde{E})$ & 0.8 & 0.6 & {$[0.4,0.9]$} \\
\hline $\operatorname{Pr}(O \mid \tilde{E})$ & 0.9 & 0.9 & {$[0.7,1.1]$} & $\operatorname{Pr}(\tilde{O} \mid \tilde{E})$ & 1.0 & 1.1 & {$[0.8,1.4]$} \\
\hline $\operatorname{Pr}(E \mid \tilde{U})$ & 7.0 & 6.2 & {$[3.2,9.1]$} & $\operatorname{Pr}(\tilde{E} \mid \tilde{U})$ & 13.9 & 12.8 & {$[8.8,16.8]$} \\
\hline $\operatorname{Pr}(U \mid \tilde{U})$ & 77.8 & 78.1 & {$[73.6,82.6]$} & $\operatorname{Pr}(\tilde{U} \mid \tilde{U})$ & 79.5 & 80.5 & {$[74.8,86.3]$} \\
\hline $\operatorname{Pr}(O \mid \tilde{U})$ & 15.2 & 15.8 & {$[11.4,20.2]$} & $\operatorname{Pr}(\tilde{O} \mid \tilde{U})$ & 6.6 & 6.7 & {$[2,11.4]$} \\
\hline $\operatorname{Pr}(E \mid \tilde{O})$ & 1.4 & 1.3 & {$[0.9,1.7]$} & $\operatorname{Pr}(\tilde{E} \mid \tilde{O})$ & 1.4 & 1.6 & {$[0.9,2.2]$} \\
\hline $\operatorname{Pr}(U \mid \tilde{O})$ & 1.0 & 1.0 & {$[0.5,1.5]$} & $\operatorname{Pr}(\tilde{U} \mid \tilde{O})$ & 0.9 & 1.0 & {$[0.2,1.7]$} \\
\hline $\operatorname{Pr}(O \mid \tilde{O})$ & 97.5 & 97.7 & {$[97,98.3]$} & $\operatorname{Pr}(\tilde{O} \mid \tilde{O})$ & 97.7 & 97.5 & {$[96.5,98.4]$} \\
\hline
\end{tabular}

Note: Bootstrap Confidence Interval based on 500 simulations are reported in [].

$B^{D G P}:$

$$
\begin{gathered}
B^{D G P}=\left[\begin{array}{ccc}
b_{11} & b_{12} & b_{13} \\
b_{21} & b_{22} & b_{23} \\
b_{31} & b_{32} & b_{33}
\end{array}\right] \\
B_{\max }^{D G P}=\left[\begin{array}{ccc}
1-\bar{b}_{12}-\bar{b}_{13} & \bar{b}_{12} & \bar{b}_{13} \\
\bar{b}_{21} & 1-\bar{b}_{21}-\bar{b}_{23} & \bar{b}_{23} \\
\bar{b}_{31} & \bar{b}_{32} & 1-\bar{b}_{31}-\bar{b}_{32}
\end{array}\right], \\
B_{\min }^{D G P}=\left[\begin{array}{ccc}
1-\underline{\mathrm{b}}_{12}-\underline{\mathrm{b}}_{12} & \underline{\mathrm{b}}_{12} & \underline{\mathrm{b}}_{12} \\
\underline{\mathrm{b}}_{21} & 1-\underline{\mathrm{b}}_{21}-\underline{\mathrm{b}}_{23} & \underline{\mathrm{b}}_{23} \\
\underline{\mathrm{b}}_{31} & \underline{\mathrm{b}}_{32} & 1-\underline{\mathrm{b}}_{31}-\underline{\mathrm{b}}_{32}
\end{array}\right]
\end{gathered}
$$

Table 9 and 10 compare the estimated results of misclassification matrices for the data simulated based on $B_{\max }^{D G P}$ and $B_{\min }^{D G P}$. For $B_{\max }^{D G P}$, the true parameters are within the $95 \%$ confidence interval of the estimated $B_{\max }^{\text {Estimate }}$. On the other hand, some of the misclassificiation probabilities in $B_{\max }^{D G P}$ are close to $B_{\max }^{E s t i m a t e}$ but do not fall in its $95 \%$ confidence interval. 
Table 9: $B_{\max }^{D G P}$ vs $B_{\text {max }}^{\text {Estimate }}$

\begin{tabular}{|c|c|c|c|c|c|c|c|}
\hline \multicolumn{4}{|c|}{$\begin{array}{c}\text { (1) Misclassification Probabilities (Max) } \\
\operatorname{Pr}(j \mid \tilde{i})=\operatorname{Pr}\left(Y_{t}=j \mid \tilde{Y}_{t}=i\right) \text { for } i, j \in\{E, U, O\} \\
\text { (In percentage points) }\end{array}$} & \multicolumn{4}{|c|}{$\begin{array}{c}\text { (2) Transition Probabilities (Max) } \\
\operatorname{Pr}(\tilde{j} \mid \tilde{i})=\operatorname{Pr}\left(\tilde{Y}_{t+1}=j \mid \tilde{Y}_{t}=i\right) \text { for } i, j \in\{E, U, O\} \\
\text { (In percentage points) }\end{array}$} \\
\hline & (1) & $(2)$ & $(3)$ & & (1) & $(2)$ & (3) \\
\hline & $B_{\max }^{D G P}$ & $B_{\max }^{\text {Estimate }}$ & $95 \% C I_{\max }$ & & $A^{\text {Implied }}$ & $A_{m i n}^{e s t}$ & $95 \% \mathrm{CI}$ \\
\hline $\operatorname{Pr}(E \mid \tilde{E})$ & 98.5 & 98.5 & {$[98.4,98.6]$} & $\operatorname{Pr}(\tilde{E} \mid \tilde{E})$ & 98.3 & 98.4 & {$[98.2,98.5]$} \\
\hline $\operatorname{Pr}(U \mid \tilde{E})$ & 0.5 & 0.5 & {$[0.4,0.6]$} & $\operatorname{Pr}(\tilde{U} \mid \tilde{E})$ & 0.8 & 0.7 & {$[0.5,0.8]$} \\
\hline $\operatorname{Pr}(O \mid \tilde{E})$ & 1 & 1 & {$[0.9,1.1]$} & $\operatorname{Pr}(\tilde{O} \mid \tilde{E})$ & 1.0 & 1 & {$[0.8,1.1]$} \\
\hline $\operatorname{Pr}(E \mid \tilde{U})$ & 8.4 & 8.4 & {$[7,9.7]$} & $\operatorname{Pr}(\tilde{E} \mid \tilde{U})$ & 13.9 & 12.6 & {$[10.9,14.3]$} \\
\hline $\operatorname{Pr}(U \mid \tilde{U})$ & 74.7 & 74.8 & {$[72.8,76.7]$} & $\operatorname{Pr}(\tilde{U} \mid \tilde{U})$ & 79.5 & 81.1 & {$[78.6,83.6]$} \\
\hline $\operatorname{Pr}(O \mid \tilde{U})$ & 16.9 & 16.9 & {$[15.2,18.6]$} & $\operatorname{Pr}(\tilde{O} \mid \tilde{U})$ & 6.6 & 6.3 & {$[4.4,8.3]$} \\
\hline $\operatorname{Pr}(E \mid \tilde{O})$ & 1.6 & 1.6 & {$[1.4,1.8]$} & $\operatorname{Pr}(\tilde{E} \mid \tilde{O})$ & 1.4 & 1.4 & {$[1.1,1.7]$} \\
\hline $\operatorname{Pr}(U \mid \tilde{O})$ & 1.2 & 1.2 & {$[1,1.4]$} & $\operatorname{Pr}(\tilde{U} \mid \tilde{O})$ & 0.9 & 1 & {$[0.6,1.3]$} \\
\hline $\operatorname{Pr}(O \mid \tilde{O})$ & 97.2 & 97.2 & {$[96.9,97.4]$} & $\operatorname{Pr}(\tilde{O} \mid \tilde{O})$ & 97.7 & 97.6 & {$[97.2,98]$} \\
\hline
\end{tabular}

Note: Bootstrap Confidence Interval based on 500 simulations are reported in [].

However, it is important to note that the distribution of true labor force history $\operatorname{Pr}\left(\tilde{Y}_{t}=\right.$ $\left.k, \tilde{Y}_{t-1}=j, \tilde{Y}_{t-2}=i\right)^{D G P}$ for $i, j, k \in\{E, U, O\}$ and that of implied true labor force history implied by the estimated hidden Markov model $(\mathrm{HMM}), \operatorname{Pr}\left(\tilde{Y}_{t}=k, \tilde{Y}_{t-1}=j, \tilde{Y}_{t-2}=i\right)^{\text {Estimate }}$ are very close. The weighted mean absolute errors (WMAE) for all possible transitions (27 possible labor force history) between the true DGP and the estimated models are 0.0014 percentage points (relative to an average probability of 3.7 percent in a possible employment path) for $B^{D G P}$. The WMAE for max and min cases are 0.001 and 0.06 percentage points. This level of accuracy in estimating the underlying distribution of true labor force history, $\operatorname{Pr}\left(\tilde{Y}_{t}=k, \tilde{Y}_{t-1}=j, \tilde{Y}_{t-2}=i\right)$ for $i, j, k \in\{E, U, O\}$ is reflected in the fact that the estimated first order transition probabilities for the true underlying labor force status (Column 2 in Table 9 and 10) capture the true transition probabilities implied by DGP, although the transitions in nonparticipation margin could be slightly less robust. Therefore, the assumption of the first order Markov process for the true labor force status is generally robust. 
Table 10: $B_{\min }^{D G P}$ vs $B_{\text {min }}^{\text {Estimate }}$

\begin{tabular}{|c|c|c|c|c|c|c|c|}
\hline \multicolumn{4}{|c|}{$\begin{array}{c}\text { (1) Misclassification Probabilities (Min) } \\
\operatorname{Pr}(j \mid \tilde{i})=\operatorname{Pr}\left(Y_{t}=j \mid \tilde{Y}_{t}=i\right) \text { for } i, j \in\{E, U, O\} \\
\text { (In percentage points) }\end{array}$} & \multicolumn{4}{|c|}{$\begin{array}{c}\text { (2) Transition Probabilities (Min) } \\
\operatorname{Pr}(\tilde{j} \mid \tilde{i})=\operatorname{Pr}\left(\tilde{Y}_{t+1}=j \mid \tilde{Y}_{t}=i\right) \text { for } i, j \in\{E, U, O\} \\
\text { (In percentage points) }\end{array}$} \\
\hline & (1) & $(2)$ & (3) & & (1) & $(2)$ & (3) \\
\hline & $B_{\max }^{D G P}$ & $B_{\max }^{\text {Estimate }}$ & $95 \% C I_{\max }$ & & $A^{\text {Implied }}$ & $A_{m i n}^{e s t}$ & $95 \% \mathrm{CI}$ \\
\hline $\operatorname{Pr}(E \mid \tilde{E})$ & 98.9 & 98.5 & {$[98.4,98.6]$} & $\operatorname{Pr}(\tilde{E} \mid \tilde{E})$ & 98.3 & 98.4 & {$[98.2,98.5]$} \\
\hline $\operatorname{Pr}(U \mid \tilde{E})$ & 0.3 & 0.5 & {$[0.4,0.6]$} & $\operatorname{Pr}(\tilde{U} \mid \tilde{E})$ & 0.8 & 0.7 & {$[0.6,0.8]$} \\
\hline $\operatorname{Pr}(O \mid \tilde{E})$ & 0.8 & 1 & {$[0.9,1.1]$} & $\operatorname{Pr}(\tilde{O} \mid \tilde{E})$ & 1.0 & 1 & {$[0.8,1.1]$} \\
\hline $\operatorname{Pr}(E \mid \tilde{U})$ & 5.7 & 8.4 & {$[7.1,9.7]$} & $\operatorname{Pr}(\tilde{E} \mid \tilde{U})$ & 13.9 & 12.6 & {$[11,14.2]$} \\
\hline $\operatorname{Pr}(U \mid \tilde{U})$ & 80.9 & 74.5 & {$[72.5,76.6]$} & $\operatorname{Pr}(\tilde{U} \mid \tilde{U})$ & 79.5 & 81.2 & {$[78.6,83.9]$} \\
\hline $\operatorname{Pr}(O \mid \tilde{U})$ & 13.5 & 17.1 & {$[15.4,18.8]$} & $\operatorname{Pr}(\tilde{O} \mid \tilde{U})$ & 6.6 & 6.2 & {$[3.9,8.4]$} \\
\hline $\operatorname{Pr}(E \mid \tilde{O})$ & 1.2 & 1.4 & {$[1.2,1.7]$} & $\operatorname{Pr}(\tilde{E} \mid \tilde{O})$ & 1.4 & 0.7 & {$[0.4,1]$} \\
\hline $\operatorname{Pr}(U \mid \tilde{O})$ & 0.8 & 1 & {$[0.8,1.3]$} & $\operatorname{Pr}(\tilde{U} \mid \tilde{O})$ & 0.9 & 0.5 & {$[0.1,0.8]$} \\
\hline $\operatorname{Pr}(O \mid \tilde{O})$ & 97.9 & 97.5 & {$[97.2,97.9]$} & $\operatorname{Pr}(\tilde{O} \mid \tilde{O})$ & 97.7 & 98.8 & {$[98.4,99.3]$} \\
\hline
\end{tabular}

Note: Bootstrap Confidence Interval based on 500 simulations are reported in [].

\section{References}

[1] Allman, E. S., Matias, C., and Rhodes, J. A. (2009), "Identifiability of Parameters in Latent Structure Models with Many Observed Variables," Annals of Statistics, 37.6A, 3099-3132.

[2] Feng, S., and Hu, Y. (2013), "Misclassification Errors and the Underestimation of the US Unemployment Rate," American Economic Review, 103.2, 1054-1070.

[3] Hu, Y. (2008), "Identification and Estimation of Nonlinear Models with Misclassification Error using Instrumental Variables: a General Solution," Journal of Econometrics, 144, $27-61$.

[4] Kruskal, J. B. (1976), "More Factors than Subjects, Tests and Treatments: An Indeterminacy Theorem for Canonical Decomposition and Individual Differences Scaling," Psychometrika, 41.3, 281-93. 